\title{
On the formation of streamwise vortices by plasma vortex generators
}

\author{
Timothy N. Jukes and Kwing-So Choi $\dagger$ \\ Faculty of Engineering, University of Nottingham, University Park, \\ Nottingham NG7 2RD, United Kingdom \\ (Received 3 April 2013; revised 8 July 2013; accepted 7 August 2013; \\ first published online 23 September 2013)
}

The streamwise vortices generated by dielectric-barrier-discharge plasma actuators in the laminar boundary layer were investigated using particle image velocimetry to understand the vortex-formation mechanisms. The plasma vortex generator was oriented along the primary flow direction to produce a body force in the spanwise direction. This created a spanwise-directed wall jet which interacted with the oncoming boundary layer to form a coherent streamwise vortex. It was found that the streamwise vortices were formed by the twisting and folding of the spanwise vorticity in the oncoming boundary layer into the outer shear layer of the spanwise wall jet, which added its own vorticity to increase the circulation along the actuator length. This is similar to the delta-shaped, vane-type vortex generator, except that the circulation was enhanced by the addition of the vorticity in the plasma jet. It was also observed that the plasma vortex was formed close to the wall with an enhanced wall-ward entrainment, which created strong downwash above the actuator.

Key words: boundary layer control, plasmas, vortex dynamics

\section{Introduction}

\subsection{Dielectric-barrier-discharge plasma actuators}

Dielectric-barrier-discharge (DBD) plasma actuators are purely electric devices which can directly couple momentum into gas flows. This has led to much interest for flow control applications since they are simple, flush mountable and can be rapidly activated on demand. A typical plasma actuator consists of two electrodes separated by a dielectric layer, as shown in figure 1. This is an uncoiled parallel plate geometry, which has been used for ozone generation since 1857 (see Kogelschatz, Eliasson \& Egli 1997), but allows plasma to be formed over the surface of an aerodynamic body rather than volumetrically.

DBD plasma is created when sufficient voltage is applied between the upper, exposed electrode and the lower, encapsulated electrode to initiate ionization of the 


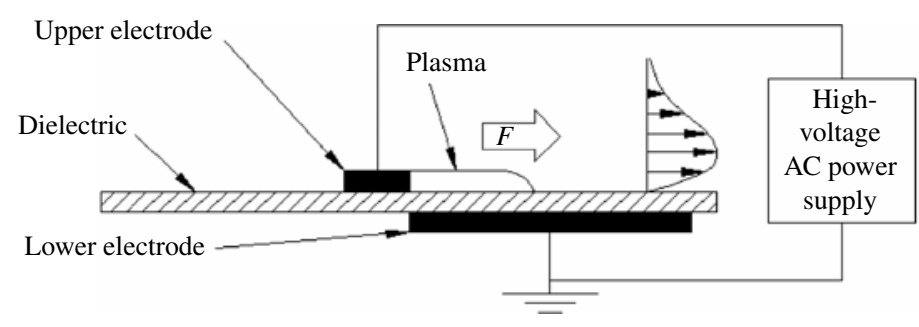

FIGURE 1. Typical construction of a DBD plasma actuator. Dielectric thickness $\sim O(1 \mathrm{~mm})$, electrode thickness $\sim O(10 \mu \mathrm{m})$ and electrode width $\sim O(10 \mathrm{~mm})$.

ambient gas (several kilovolts in atmospheric air). This causes weakly ionized glow discharge plasma to spread out for a few millimetres from the edge of the exposed electrode to the side under which the lower electrode is placed. The discharge is selflimiting (Enloe et al. 2004a,b), whereby charge emitted from the exposed electrode gradually accumulates on the dielectric surface and reduces the applied potential difference. This quenches further plasma formation unless the exposed electrode potential continually increases. These actuators are therefore usually excited by ac voltage to allow continuous plasma generation albeit intermittently throughout the ac cycle. The discharge characteristics are subtly different depending on the excitation polarity, where the positive-going cycle is filamentary with randomly spaced shortduration streamer discharges whilst the negative-going cycle has increased spatial uniformity with plume-shaped corona discharges (Gibalov \& Pietsch 2000; Enloe et al. 2004a,b; Benard \& Moreau 2012).

Plasma actuators generate an electrohydrodynamic (EHD) body force. This transfers momentum through a collisional mechanism from charged particles accelerated by the electric field to neutral particles in the surrounding gas (Boeuf et al. 2007). This induces a net flow away from the exposed electrode, with direction to the right in figure 1. The body force creates starting vortices in quiescent air (Whalley \& Choi 2012) followed by a quasi-steady laminar wall jet (Jukes et al. 2006a) with characteristics similar to a classic wall jet that issues from a thin slit and passes over a flat plate (Glauert 1956). Jet velocities are typically a few metres per second with a jet thickness of a few millimetres (Forte et al. 2007).

\subsection{DBD plasma flow control}

DBD plasma actuators have received considerable attention for aerodynamic applications since around the start of this millennium (Moreau 2007). Roth, Sherman \& Wilkinson (2000) demonstrated that these actuators can cause significant changes in friction drag on a flat plate boundary layer. This has spurred a plethora of studies, particularly in low-Reynolds-number air flows, with the aim of drag reduction (Wilkinson 2003; Jukes et al. 2006b; Choi, Jukes \& Whalley 2011), lift enhancement (Little et al. 2010; Feng et al. 2012; Greenblatt, Schneider \& Schule 2012), flow separation control (Post \& Corke 2006; He, Corke \& Patel 2009; Schatzman \& Thomas 2010), vortex shedding control (Thomas, Kozlov \& Corke 2008; Jukes \& Choi 2009a,b,c), transition control (Grundmann \& Tropea 2008; Hanson et al. 2010) and noise control (Huang \& Zhang 2008). Further information on operating principles and flow control applications can be found in the review articles by Moreau (2007), Corke, Post \& Orlov (2009) and Wang et al. (2013). In all of these studies, the DBD 
plasma actuator produces a body force generating a jet flow that is used to manipulate the primary flow.

For flow separation control, the usual configuration is to orient DBD actuators along the spanwise direction so that a body force is produced with the mean flow (co-flow forcing). This directly adds momentum into the boundary layer which may re-energize the fluid, promote transition or initiate instabilities so that flow separation can be delayed, controlled or completely avoided. This is most effective when the actuators are located just upstream of the separation point (Huang, Corke \& Thomas 2006a; Jukes \& Choi 2009a; Corke et al. 2011), and pulsed periodically (Corke, He \& Patel 2004; Huang, Corke \& Thomas 2006b; Greenblatt et al. 2008; Jukes \& Choi 2009b), which can be utilized in efficient flow control strategies (Jukes \& Choi 2009c).

\subsection{Vortex generators}

Vortex generators (VGs) can prevent flow separation by enhancing the mixing between the boundary layer and the free stream, so that high-momentum fluid is brought from the outer flow into the near-wall region. This re-energizes the near-wall fluid, allowing it to withstand more severe adverse pressure gradients before separation. Vane-type VGs have been a subject of study since the 1940s (Taylor 1947). These are typically thin plates which protrude into the flow, which have found practical application on many commercial aircraft and in industry. There are a huge number of different designs, for which the reader is referred to Schubauer \& Spangenberg (1960) and Lin (2002).

The success of vane-type VGs stems from the fact that streamwise vortices have remarkable organization and longevity (Bushnell 1992), enabling their use for a diverse range of flow separation control applications. Plus they are cheap, simple and can be retrofitted to problem areas. Vane-type VGs typically have height of the order of the boundary-layer thickness, $h / \delta=1$ ( $\delta$-scale VGs), although recent studies suggest smaller devices with $h / \delta=0.1-0.5$ minimize the device drag without hindering performance (low-profile VGs, see Lin (2002)). Detailed measurements of the flow structure of streamwise vortices and vortex pairs have been made by Shebaka, Mehta \& Bradshaw (1985), Mehta \& Bradshaw (1988), Pauley \& Eaton (1988), Yao, Lin \& Allen (2002) and Angele \& Grewe (2007). Godard \& Stanislas (2006) optimized VG geometry over a bump and found peak performance with triangular vanes of height $h / \delta=0.37$, length $l / h=2$, yaw angle $\beta=18^{\circ}$ and spanwise spacing $\lambda / h=6$.

However, vane-type VGs incur an inherent drag penalty and they are only required during off-design conditions or select parts of the flight envelope. It is therefore of interest to actively generate streamwise vortices through non-intrusive means. An alternative technique is vortex generator jets (VGJs), for which fluid is ejected from small holes or slots at the wall. Counter-rotating longitudinal vortex pairs are generated by perpendicular transverse jets through tilting and folding of the jet shear layers (Kelso, Lim \& Perry 1996; Cortelezzi \& Karagozian 2001), whilst pitching and skewing the jet allows concentration of one of the vortex pairs to form a single streamwise vortex (Khan \& Johnston 2000). Johnston \& Nishi (1990) demonstrated VGJs and their ability to reduce flow separation, whilst detailed measurements have been made by Zhang (2003) and the topic is reviewed by Johnston (1999).

\subsection{DBD plasma VGs}

DBD-VGs offer another alternative to vane-type VGs. These devices should be without the profile drag penalty since they are flush mounted and can be rapidly switched 
on and off as required. In addition they do not require ducting or holes in the aerodynamic surface, unlike VGJs. DBD-VGs should offer increased versatility over co-flow plasma actuators since this flow control strategy relies on the action of streamwise vortices rather than direct addition of momentum close to the separation point.

DBD-VGs are plasma actuators aligned with, or with yaw to, the primary flow direction. This produces a body force with component into the spanwise direction that can, under certain circumstances, generate longitudinal vortices (Jukes, Segawa \& Furutani 2013). The concept can be traced back to Roth, Sherman \& Wilkinson (1998), where symmetric, streamwise-oriented plasma actuators produced EHD forcing in both positive and negative spanwise directions to produced counter-rotating vortex pairs with common-flow down arrangement. This increased the skin friction in a laminar boundary layer through promoting transition.

Jukes \& Choi (2012) investigated a single DBD-VG in a laminar boundary layer. They studied the development of the streamwise vortex using cross-stream particle image velocimetry (PIV), and parametrically studied the effect of plasma-induced and free-stream velocity, DBD-VG length and electrode yaw angle. Actuators placed at $90^{\circ}$ to the oncoming flow produced the strongest vortex, whilst the circulation increased with both electrode length and plasma-to-free-stream velocity ratio. Corotating and counter-rotating $\mathrm{DBD}-\mathrm{VG}$ arrays and their effectiveness of separation control over a trailing edge ramp were demonstrated, where flow control was possible even at velocity ratio less than $10 \%$. For aerofoil applications, Okita et al. (2008) observed that a large-scale streamwise vortex was produced by a single DBD-VG which significantly delayed separation over a NACA 0024 aerofoil. Jukes et al. (2013) applied co-rotating and counter-rotating DBD-VG arrays and confirmed effective flow separation control on a NACA 4418 aerofoil at low Reynolds number. Moreover, DBD-VGs outperformed co-flow DBD actuators by increasing the range of angle of attack at which they were effective. This confirms that DBD-VGs are less sensitive to location and are particularly useful when the separation line is curvilinear, unknown or moves dynamically.

For boundary-layer control, He, Corke \& Patel (2007) studied turbulent separation over a ramp model, which is possibly the earliest reference to plasma VGs. Flow visualization revealed that symmetric streamwise actuators generate counter-rotating vortices similar to vane-type VGs, which could improve the pressure recovery over the ramp. Schatzman \& Thomas (2010) observed that DBD-VGs could be just as effective as co-flow actuators in a similar configuration. Grundmann, Sayles \& Eaton (2011) and Grundmann et al. (2012) found a significant improvement with DBD-VGs for controlling the separation bubble in a three-dimensional diffuser, where the effect was very similar to vane-type VGs with height $h / \delta \approx 0.3-0.6$. In addition, these actuators have recently been demonstrated to produce streamwise vortices in relatively high-speed turbulent flow (Wicks et al. 2012).

Chan, Zhang \& Gabriel (2007) and Huang \& Zhang (2008) used DBD-VGs for noise control upstream of a rectangular cavity. The streamwise vortices impeded development of organized structures within the cavity, which disrupted the fluidacoustic feedback mechanism to reduce the aerodynamic noise. Kozlov \& Thomas (2011) reduced aerodynamic noise by using DBD-VGs to introduce streamwise vorticity in the separating shear layers around a circular cylinder, which disrupted the large-scale vortex shedding.

DBD-VGs have also been used to control supersonic flow (Im, Do \& Cappelli 2010) and delay bypass transition (Hanson et al. 2010). Plasma-based VGs have 


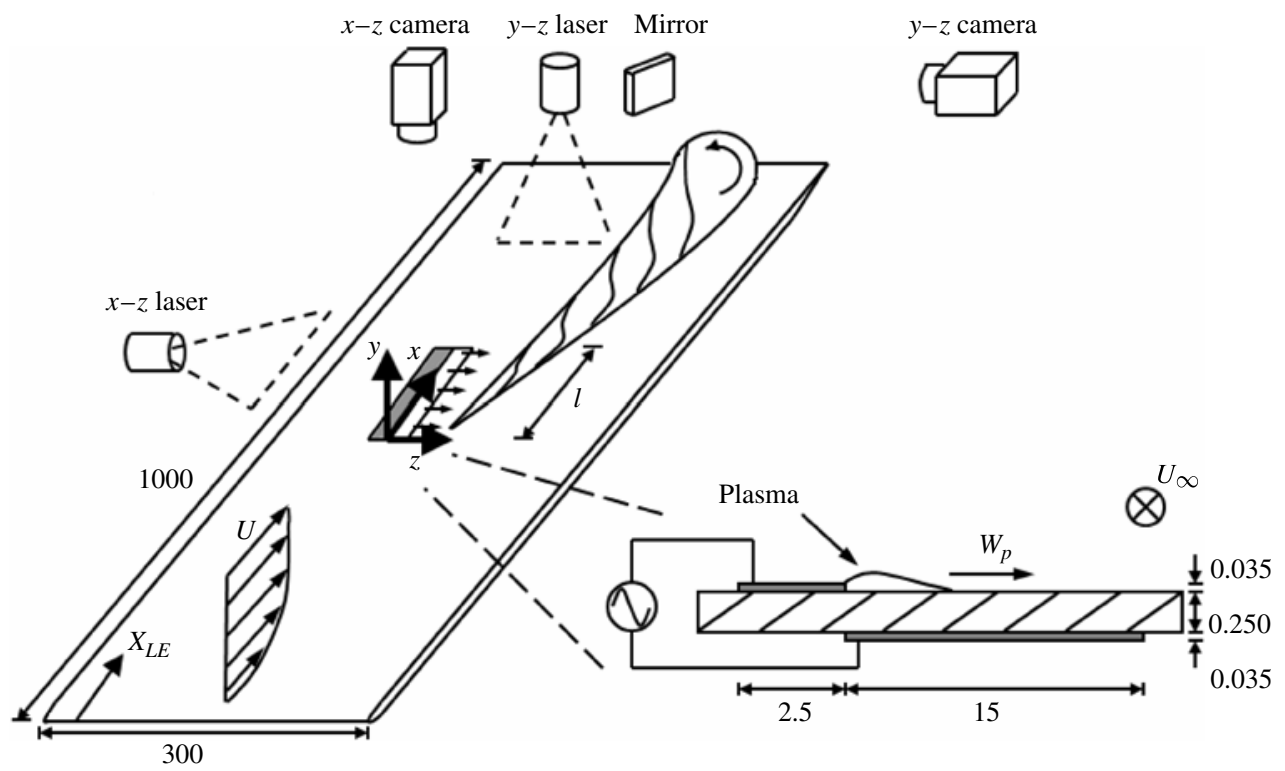

FIGURE 2. Schematic of experimental set-up. All dimensions are in millimetres. DBD-VG and streamwise vortex not to scale.

also been proposed based on differentially energizing DBD actuator pairs to create contra-rotating vortices and vectored jets (Benard et al. 2008b).

This article extends the parametric study of Jukes \& Choi (2012) to provide a more in-depth understanding of the mechanisms of streamwise vortex generation by plasma VGs. Unlike previously published work, volumetric three-component velocity information is presented here in close proximity to both DBD-VGs and vane-type VGs in a laminar boundary layer. Our aim is to fully understand the streamwise vortex-formation mechanisms and make a comparison with traditional VGs. The experimental set-up is explained in $\S 2$, whilst $\S 3$ characterizes the plasma-induced flow in initially quiescent air. The DBD-VG streamwise vortex-formation mechanisms are then identified and discussed in detail in $\S 4$ and the streamwise vortex scaling is explained in $\S 5$. Finally, the DBD-VG is compared with a typical $\delta$-scale (rectangular profile) and a low-profile (half-delta) VG in $\S 6$, where differences in vortex trajectory and circulation are quantified and discussed. These results greatly enhance our understanding of the streamwise vortex-formation mechanisms and allows direct comparison between classic and plasma VGs.

\section{Experimental set-up}

Experiments were conducted in an open-return wind tunnel with acrylic test section of $1.5 \mathrm{~m} \times 0.3 \mathrm{~m} \times 0.3 \mathrm{~m}$. A $1 \mathrm{~m}$ long, smooth horizontal plate spanned the tunnel, $0.1 \mathrm{~m}$ above the lower wall and $0.15 \mathrm{~m}$ after a 7:1 area ratio contraction. The plate was manufactured from $10 \mathrm{~mm}$ thick acrylic with super-elliptic leading edge and sharp trailing edge, as illustrated in figure 2. Both DBD-VGs and vane-type VGs were placed at the wind tunnel centreline at streamwise distance $x_{L E}=0.6 \mathrm{~m}$ from the leading edge $\left(R e_{x_{L E}}=85000\right)$ on a flush-mounted removable test plate. Co-ordinates are defined from the VG tip where $x, y$ and $z$ denote the streamwise, wall-normal and 


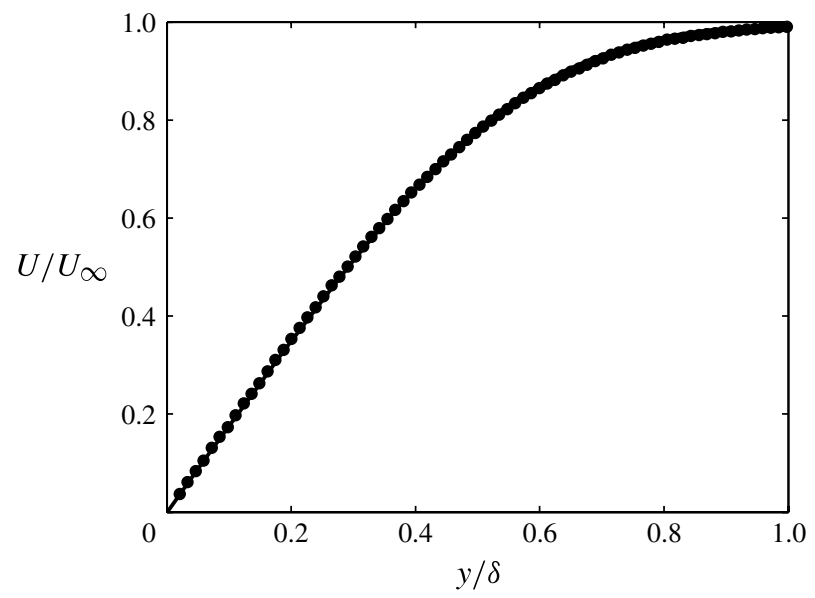

FIGURE 3. Boundary-layer profile at the VG tip: $\bullet R e_{x}=85000 ;-$ Blasius profile.

spanwise directions, respectively. To ensure a thick boundary layer at the measurement station the free-stream velocity was fixed at $U_{\infty}=2.15 \mathrm{~m} \mathrm{~s}^{-1}$, where the free-stream turbulence intensity was $0.25 \%$. The boundary layer along the entire plate was initially studied using PIV without any VGs. There was no evidence of flow separation at the leading edge and the centreline boundary-layer thickness, $\delta$, developed within $\pm 6 \%$ of that predicted by laminar boundary layer theory, $\delta / x_{L E}=5.0 R e_{x_{L E}}^{-0.5}$ (Schlichting 1979). At the start of the VGs, the boundary-layer thickness $\delta=10.5 \mathrm{~mm}$, and the shape factor $H=2.44$. Boundary-layer measurements are shown in figure 3 , illustrating a close fit to the Blasius solution.

Two DBD-VGs were studied with identical construction but with different length, l. Both were asymmetric-type actuators with upper, exposed electrode $2.5 \mathrm{~mm}$ wide and lower, encapsulated electrode $15 \mathrm{~mm}$ wide, as shown on the right-hand side of figure 2. The electrodes were $35 \mu \mathrm{m}$ copper separated by $250 \mu \mathrm{m}$ thick polyimide $\left(\right.$ Cirlex $\left.^{\circledR}\right)$ dielectric. The protrusion of the upper electrodes from the wall $\left(R e_{h}=5\right)$ is expected to have negligible effect on the boundary layer profile. All designs were photochemically etched onto the substrate using PCB manufacturing techniques. The electrodes were staggered so that the upper electrode leading edge was exactly at the lower electrode trailing edge (i.e. no overlap or gap). This produced plasma on one side of the upper electrode only, so that a unidirectional body force was produced. (Note that counter-rotating DBD-VGs can be produced simply by extending the lower electrode to produce plasma on both sides of the upper electrode.) Both actuators were aligned along the streamwise direction $\left(\beta=90^{\circ}\right)$, so that the body force acted in the $+z$-direction only. This is the optimum configuration for streamwise vortex generation, as discussed by Jukes \& Choi (2012). DBD-VG1 had length, $l / \delta=5.7$ whilst DBD-VG2 had $l / \delta=1.9$, which is the same streamwise length as the $\delta$-scale VG so that a direct comparison can be made between DBD-VG2 and vane-type VGs (scaling with the undisturbed laminar $\delta$ at the VG tip is applied throughout this article). Both DBD-VGs were excited with sinusoidal waveform from a PSI-PG1040F power supply at a frequency $f=22.8 \mathrm{kHz}$ with voltage amplitude, $E$, and other parameters documented in table 1 . The power input was estimated through integrating voltage and current waveforms to be 125 and $80 \mathrm{~W}$ for DBD-VG1 and DBD-VG2, respectively. 


$\begin{array}{lccccccccc}\text { DBD-VG } & \begin{array}{c}E \\ \left(\mathrm{kV}_{p-p}\right)\end{array} & \begin{array}{c}l \\ (\mathrm{~mm})\end{array} & \begin{array}{c}\delta_{p} \\ (\mathrm{~mm})\end{array} & \begin{array}{c}W_{p} \\ \left(\mathrm{~m} \mathrm{~s}^{-1}\right)\end{array} & \begin{array}{c}V_{p} \\ \left(\mathrm{~m} \mathrm{~s}^{-1}\right)\end{array} & l / \delta & \delta_{p} / \delta & W_{p} / U_{\infty} & V_{p} / U_{\infty} \\ \text { DBD-VG1 } & 7.5 & 60 & 0.55 & 3.47 & -0.83 & 5.71 & 0.052 & 1.62 & -0.39 \\ \text { DBD-VG2 } & 7.0 & 20 & 0.56 & 2.70 & -0.77 & 1.90 & 0.053 & 1.25 & -0.36\end{array}$

TABLE 1. DBD-VG parameters.

$\begin{array}{lccccccc}\text { Vane-VG } & \begin{array}{c}\beta \\ \left({ }^{\circ}\right)\end{array} & \begin{array}{c}l \\ (\mathrm{~mm})\end{array} & \begin{array}{c}h \\ (\mathrm{~mm})\end{array} & \begin{array}{c}U_{h} \\ \left(\mathrm{~m} \mathrm{~s}^{-1}\right)\end{array} & l \cos \beta / \delta & h / \delta & U_{h} / U_{\infty} \\ \text { BL-VG } & 16 & 21 & 10.5 & 2.15 & 1.92 & 1.00 & 1.00 \\ \text { LP-VG } & 20 & 10 & 6.0 & 1.76 & 0.89 & 0.57 & 0.82\end{array}$

TABLE 2. Vane-VG parameters.

Lower voltage was applied to DBD-VG2 to attempt to match the maximum plasma-jet velocity, $W_{p}$, to the streamwise velocity at the tip of the $\delta$-scale $\mathrm{VG}$, for which $U_{h}=U_{\infty}$. This will be discussed in more detail in $\S 3$.

Two vane-type VGs were manufactured from $0.15 \mathrm{~mm}$ thick shim steel. One was rectangular shaped with height, $h / \delta=1$ and length, $l / h=2$, and was set with yaw, $\beta=16^{\circ}$ to the streamwise direction. This $\delta$-scale VG (BL-VG) is a typical geometry, identical to that studied by Yao et al. (2002), albeit at lower Reynolds number herein. The second vane-type VG was triangular shaped (half-delta), with tip height $h / \delta=0.57, l / h=1.7$ and $\beta=20^{\circ}$. This low-profile VG (LP-VG) is similar to the optimum geometry reported by Godard \& Stanislas (2006). The vane-type VG parameters are documented in table 2.

The flow field around all VGs was studied with a Dantec dynamics two-dimensional PIV system in both the $x-z$ and $y-z$ planes. The system consisted of a Litron LDY302PIV $15 \mathrm{~mJ}$ per pulse Nd:YLF laser, a Vision Research Phantom V12 high-speed camera and a dedicated PC. Olive oil seeding particles of nominally $1 \mu \mathrm{m}$ diameter were introduced upstream of the wind tunnel contraction section from a TSI 9307-6 oil droplet generator via a seeding rake. The effect of charging on olive oil particles has been discussed by Stephen et al. (2011), where the effects of highly active ozone generated by the DBD plasma and the high electric field strength close to the actuator do not appear to influence the seeding particles significantly.

For PIV in the $x-z$ plane, the camera was mounted above the wind tunnel with the laser mounted from the side (see figure 2 ). $U-W$ velocity measurements were made for $0.048 \leqslant y / \delta \leqslant 1.9$ in $0.14 \delta$ increments $(0.048 \delta$ increments for $y / \delta \leqslant 0.19, y \leqslant 2 \mathrm{~mm})$. A $105 \mathrm{~mm}$ macro lens viewed an area of $13.3 \delta \times 8.4 \delta(x \times z)$. The laser sheet was focused as thin as possible over this domain, where it had maximum thickness of less than $0.09 \delta(1 \mathrm{~mm})$.

For PIV in the $y-z$ plane, the laser was mounted above the wind tunnel in a three-axis traverse and defocused slightly to produce a light sheet of $0.24 \delta$ $(2.5 \mathrm{~mm})$ thickness, to allow longer transit time of the seeding particles. The camera was mounted to the side of the wind tunnel and viewed the $y-z$ plane via a $5 \delta \times 5 \delta(50 \mathrm{~mm} \times 50 \mathrm{~mm})$ high-quality mirror mounted at $45^{\circ}$ to the streamwise plane at $26 \delta$ downstream of the plate trailing edge. A $300 \mathrm{~mm}$ macro lens viewed 
an area $4.5 \delta \times 7.1 \delta(y \times z)$, and $3.0 \delta \times 4.9 \delta$ at the DBD-VG tip $(x / \delta \leqslant 1.1$, $x \leqslant 12 \mathrm{~mm})$. The $V-W$ velocity measurements were made for $-0.6 \leqslant x / \delta \leqslant 11.4$ in $0.55 \delta$ increments $(0.14 \delta$ increments for $x / \delta \leqslant 1.1)$. Within this plane, the accuracy of the PIV decreases from the centre of the image due to the apparent translation of the particles towards the edges of the frame as they travel through the laser sheet. This error lessens as the size of the image reduces or the distance between the camera and light sheet increases so that long focal length or telecentric optic are desirable. Here, the distance between the light sheet and focal plane was $105 \delta$, whilst PIV measurements were made for $y / \delta \leqslant 2.4$ with the wall at the centre of the image. The velocity measurement error at the corners of the image was less than $0.06 U_{\infty}\left(0.12 \mathrm{~m} \mathrm{~s}^{-1}\right)$. The streamwise vortex was always set in the image centre so that this error within was much less. Furthermore, the mean undisturbed flow field was subtracted from the mean flow field with the VGs to minimize the error although the total error in the PIV measurements is expected to be no better than 3-5\% (Westerweel 1997).

Velocity measurements were also made around the DBD actuators in initially static air. Here, the wind tunnel intake and exhaust were blocked to ensure quiescent conditions within the test section volume. Seeding was introduced via a nozzle, then given approximately 1 minute to resume quiescent conditions before data acquisition. The actuators were oriented perpendicular to the wind tunnel axis by rotating the test plate. Illumination was from above with the laser sheet at the actuator centrelines. The camera then viewed the DBD-VGs through the wind tunnel wall with a $105 \mathrm{~mm}$ macro lens at its closest focal distance $(1.5 \delta \times 2.5 \delta, 16 \mathrm{~mm} \times 26 \mathrm{~mm})$. This was fitted with a spectral filter to remove the plasma discharge from the images which allowed velocity vectors to be resolved within close proximity of the exposed electrode.

In all planes, image pairs were taken for time $t^{*}=t U_{\infty} / \delta=820(t=4 \mathrm{~s})$ in $t^{*}=4(20 \mathrm{~ms})$ intervals. The PIV data was then time-averaged for $40 \leqslant t^{*} \leqslant 820$ to ignore any starting transients. Image pairs were taken with multiple time delay, $\Delta t$, at each station (typically $\Delta t=125,250$ and $500 \mu \mathrm{s}$ in the $x-z$ plane and 100 and $200 \mu \mathrm{s}$ in the $y-z$ plane). PIV processing was performed using DynamicStudio V3.0, where velocity vectors were computed on $16 \times 32$ or $32 \times 32$ pixel grids with $50 \%$ overlap (interrogation area typically $0.09 \delta \times 0.18 \delta$ and $0.33 \delta \times 0.33 \delta$ in the $y-z$ and $x-z$ planes, respectively, $0.03 \delta \times 0.06 \delta$ in quiescent air). Processing was performed using a recursive cross-correlation technique with moving average validation between refinement steps. The image background was always subtracted prior to processing. The maximum seeding particle displacement was $33 \%$ of an interrogation area (10.5 pixels) in the $x-z$ plane and $22 \%$ (7 pixels) in the $y-z$ plane.

Three-component velocity data was obtained by interpolating time-averaged $x-z$ and $y-z$ data onto a $0.10 \delta \times 0.05 \delta \times 0.10 \delta$ grid $(1 \mathrm{~mm} \times 0.5 \mathrm{~mm} \times 1 \mathrm{~mm})$, whilst checking that the $W$-component velocity was a close match between both planar data sets. This allowed measurement of $U, V$ and $W$ within volume $12.4 \delta \times 1.9 \delta \times 5.7 \delta$ $(130 \mathrm{~mm} \times 20 \mathrm{~mm} \times 60 \mathrm{~mm})$. $W$ was within $\pm 0.15 U_{\infty}$ between $x-z$ and $y-z$ data, although the $y-z$ PIV captured $W$ poorly for $y / \delta<0.2$ due to high-velocity gradients close to the wall near the plasma. For this reason, $x-z$ plane data was generally used for $U$ and $W$ whilst $y-z$ plane data was used for $V$.

\section{DBD-VG characterization}

Figure 4(a) shows the time-averaged flow field induced by DBD-VG1 at the electrode centreline in initially quiescent air. The exposed electrode is drawn in black, 

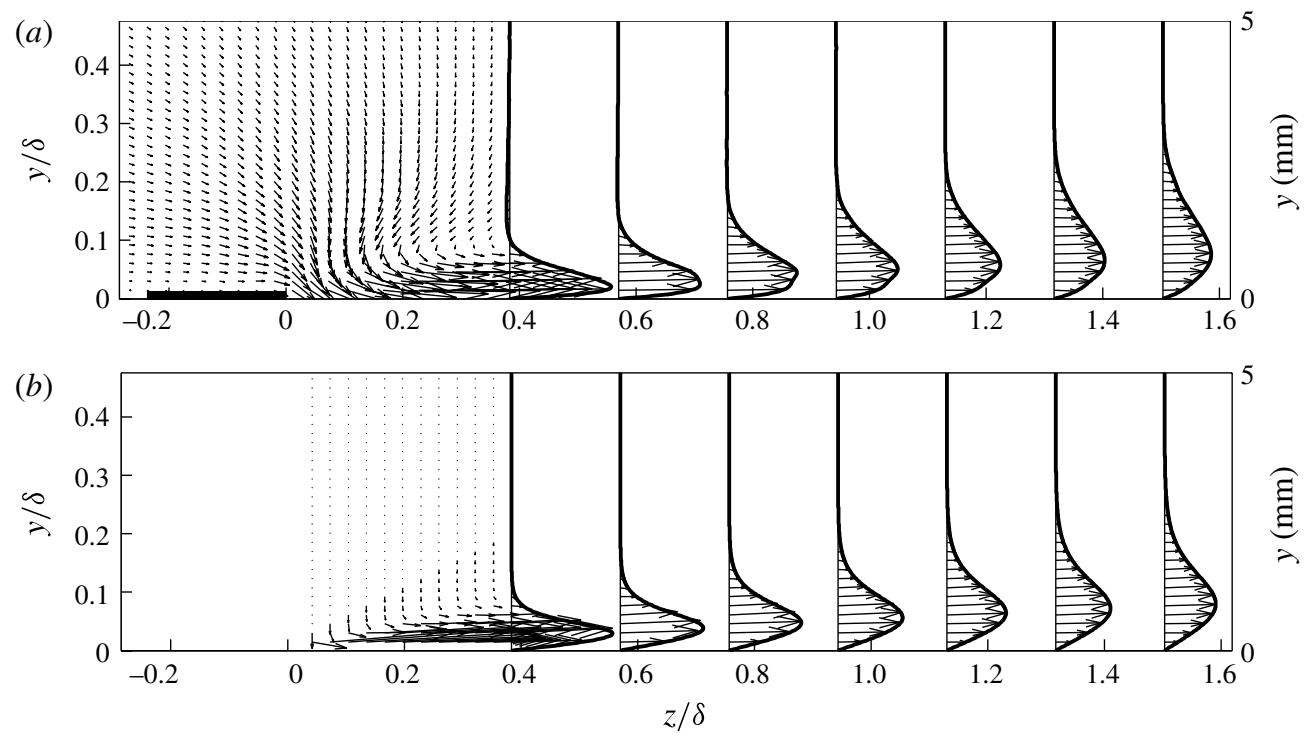

FIGURE 4. Time-averaged velocity in quiescent air: (a) DBD-VG1; (b) analytical wall jet profile (Tetervin 1948).

whilst the plasma forms in the region $0 \leqslant z / \delta \leqslant 0.3(z \lesssim 3 \mathrm{~mm})$. A jet-like velocity profile is shown emanating away from the edge of the upper electrode, whilst directly above the DBD there is a strong wall-ward velocity component because fluid is drawn into the plasma from above to replace that accelerated laterally by the EHD body force. This strong suction arises because the DBD is a source of momentum, not mass, so that fluid must be entrained from above to satisfy continuity.

Tetervin (1948) gave an analytical solution for a laminar wall jet which issues from a slit and passes over a flat plate. Scaling of the velocity profile becomes self-similar when non-dimensionalized by a reference velocity, $W_{a}$, and a reference length, $a$. Taking $W_{a}=W_{\max }$ and $a=\delta_{1 / 2}$ from the experimental data at $z=4 \mathrm{~mm}$, yields an analytic solution in figure $4(b)$ very similar to the DBD-VG except in the region around the plasma. The development of $W_{\max }$ and $\delta_{1 / 2}$ are plotted in figure 5, where the decay in jet velocity is a close match to the analytic solution $W_{\max } \sim z^{-1 / 2}$. The jet spreading rate also follows the analytic solution $\delta_{1 / 2} \sim z^{3 / 4}$ close to the actuator $(z / \delta<1)$. The deviation in the far field seems to be due to the departure from two-dimensionality.

In order to make a comparison between DBD-VGs and vane-type VGs it is important to match the length and velocity scales of the two devices. The strength of the streamwise vortex created by a vane-type VG is governed by the velocity at the vane tip (Lögdberg, Angele \& Alfredsson 2010), so that the relevant length, height and velocity scales are $l / \delta, h / \delta$ and $U_{h} / U_{\infty}$, respectively. However, DBD-VGs have no height scale since they are flush mounted, making it difficult to directly compare these two types of VG. Thus, the DBD-VG velocity and height scales must be defined at some distance downstream of the actuator. The location at which the experimental data approaches the analytic power laws is chosen for these, which can be interpreted as the distance at which the velocity profile becomes self-similar. This 

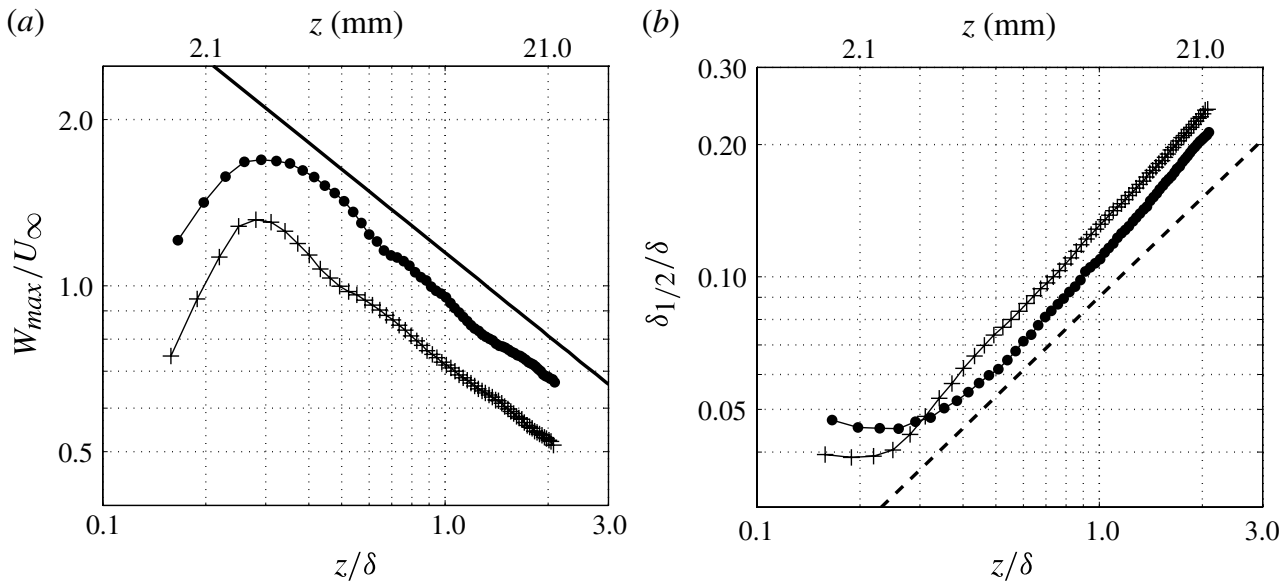

FIGURE 5. DBD-VG in quiescent air: (a) maximum jet velocity; $(b)$ jet half-thickness. DBD-VG1; + DBD-VG2. Analytical solution: $-W_{\max } \sim z^{-\frac{1}{2}} ;---\delta_{1 / 2} \sim z^{3 / 4}$.

occurs at $z=4.0$ and $3.5 \mathrm{~mm}(z / \delta=0.38$ and 0.33$)$ for DBD-VG1 and DBD-VG2, respectively, which is approximately $1 \mathrm{~mm}$ downstream of the visible glow region observed in long-exposure photographs. This decision is further supported by the high resolution PIV data of Kriegseis et al. (2012), which indicates maximum jet velocity at $z=3-4 \mathrm{~mm}$. Thus the DBD-VG velocity and height scales are given herein as $W_{p} / U_{\infty}=1.62$ and $\delta_{p} / \delta=0.052$ for DBD-VG1 and $W_{p} / U_{\infty}=1.25$ and $\delta_{p} / \delta=0.053$ for DBD-VG2. This allows a direct comparison between DBD-VG2 and BL-VG since they have identical streamwise length $(l / \delta=1.9)$ and their velocity scales are quite similar $\left(W_{p} / U_{\infty}=1.25, U_{h} / U_{\infty}=1.00\right)$. Naturally their height scales differ due to the different actuator types and the wall-ward velocity induced directly above the plasma. The maximum $-V$-component was $V_{p} / U_{\infty}=-0.39$ and -0.36 for DBD-VG1 and DBD-VG2, respectively.

An additional characterization of the DBD-VG is the magnitude of the induced body force. This can be invoked using a momentum balance across a control volume within the time-averaged flow field. Here a control volume was defined with edges at $z / \delta=-0.3, z / \delta=1.4, y / \delta=0$ and $y / \delta=0.5$ (see figure 4). Assuming steady, incompressible two-dimensional flow, whilst taking into account the self-induced drag of the actuator, the plasma force per unit width, $f_{p}$, was estimated from (Enloe et al. 2009; Versailles, Gingras-Gosselin \& Vo 2010; Kriegseis et al. 2012):

$$
f_{p}=\rho \int_{R H S} W^{2} \mathrm{~d} y-\rho \int_{L H S} W^{2} \mathrm{~d} y+\rho \int_{T O P} V W \mathrm{~d} z+\int_{W A L L} \tau_{w} \mathrm{~d} z
$$

where the wall shear stress, $\tau_{w}$, was calculated using the first velocity point above the wall assuming the no-slip condition. Thus, $f_{p}=6.7 \mathrm{mN} \mathrm{m}^{-1}$, or the total force over the actuator length, $F_{p}=0.40 \mathrm{mN}$ for DBD-VG1 $\left(f_{p}=4.7 \mathrm{mN} \mathrm{m}^{-1}\right.$ and $F_{p}=0.09 \mathrm{mN}$ for DBD-VG2). However, Jukes \& Choi (2012) found that it was the spanwise jet velocity that is the important scaling parameter for the generation of streamwise vortices by DBD-VGs. 


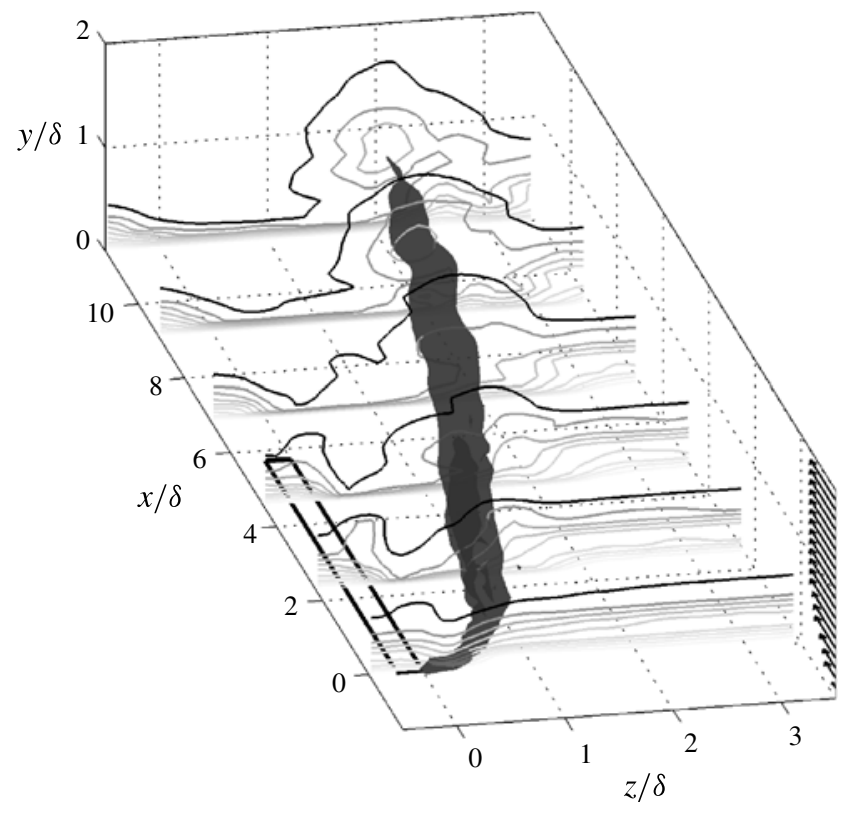

FIGURE 6. Streamwise velocity isocontours around DBD-VG1 in a laminar boundary layer: $0 \leqslant U / U_{\infty} \leqslant 0.9$ in 0.1 increments (light to dark). Vortex isosurface: $\lambda_{2}=-6.5 \times 10^{4}$ (dark grey). The DBD-VG upper electrode is marked by a black box.

\section{Vortex-formation mechanisms}

A steady longitudinal vortex can be produced when the DBD-VG is placed within a boundary layer. This is demonstrated in figure 6 , which shows streamwise velocity isocontours around DBD-VG1 with the $\lambda_{2}$ vortex indicator (Jeong \& Hussain 1995). The vortex originates at the DBD-VG tip and is initially oriented in the spanwise direction. Twisting into the streamwise direction occurs for $x / \delta \lesssim 1(x / l \lesssim 0.2)$, whilst the vortex grows in size. Thereafter, the vortex trajectory is slightly curved with approximately $10^{\circ}$ yaw to the streamwise axis. An increase in size and strength is observed along the actuator $(x / \delta \leqslant 5.7, x / l \leqslant 1)$, followed by gradual decay downstream $(x / \delta>5.7, x / l>1)$. DBD-VG2 in figure 7 shows very similar features to DBD-VG1, although the vortex is smaller and weaker due to reduced actuator length and forcing strength.

Figure 8 shows the $x-z$ plane velocity field very close to the wall. The DBD-VG creates a $+W$-component velocity due to the $+z$-directed body force. This leads to the development of a spanwise wall jet which becomes twisted into the $x$-direction by the oncoming flow. This jet initiates from the actuator edge and penetrates further into the $z$-direction with $x$. The vortex forms on the outboard edge of this jet, where figure 8 shows that the vortex trajectory closely mimics the jet footprint.

The jet shear layers are shown by the $\Omega_{x}$ isosurfaces in figure 9. The dark grey isosurface visualizes the lower shear layer of the wall jet, whilst the white isosurface shows the upper shear layer. It is the negative vorticity at the outer edge of the upper shear layer that rolls up to form the streamwise vortex. This process occurs along the entire length of the actuator so that vortex circulation increases with $x$, which will be shown in $\S 5$. In addition, the lower shear layer lifts from the wall on the outboard side of the vortex core $(z / \delta \geqslant 1)$. 


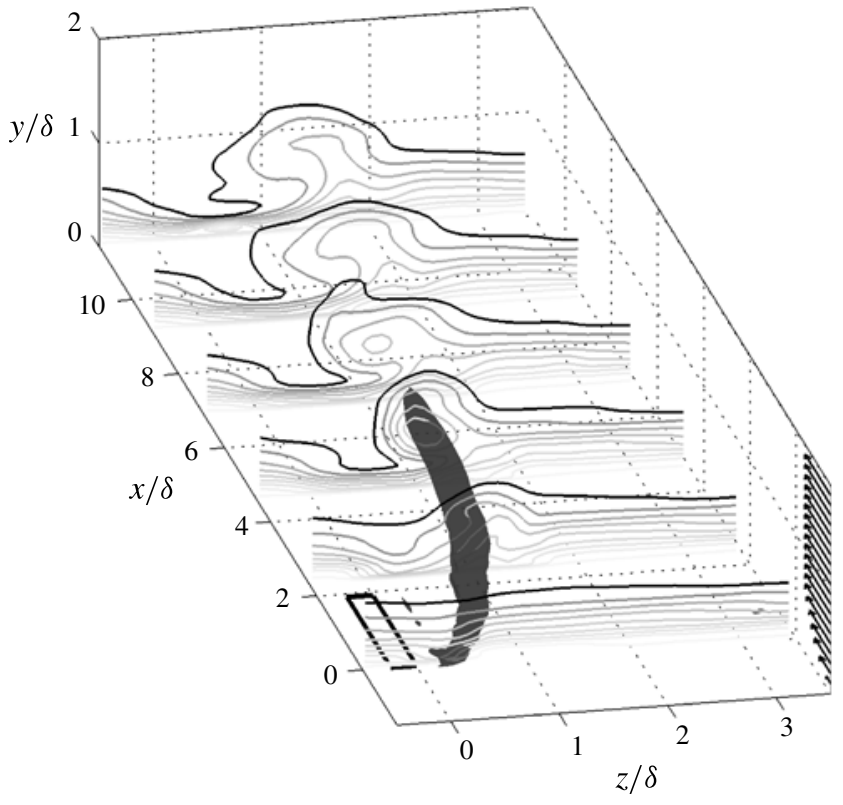

FIGURE 7. Streamwise velocity isocontours around DBD-VG2 in a laminar boundary layer: $0 \leqslant U / U_{\infty} \leqslant 0.9$ in 0.1 increments (light to dark). Vortex isosurface: $\lambda_{2}=-6.5 \times 10^{4}$ (dark grey). The DBD-VG upper electrode is marked by a black box.

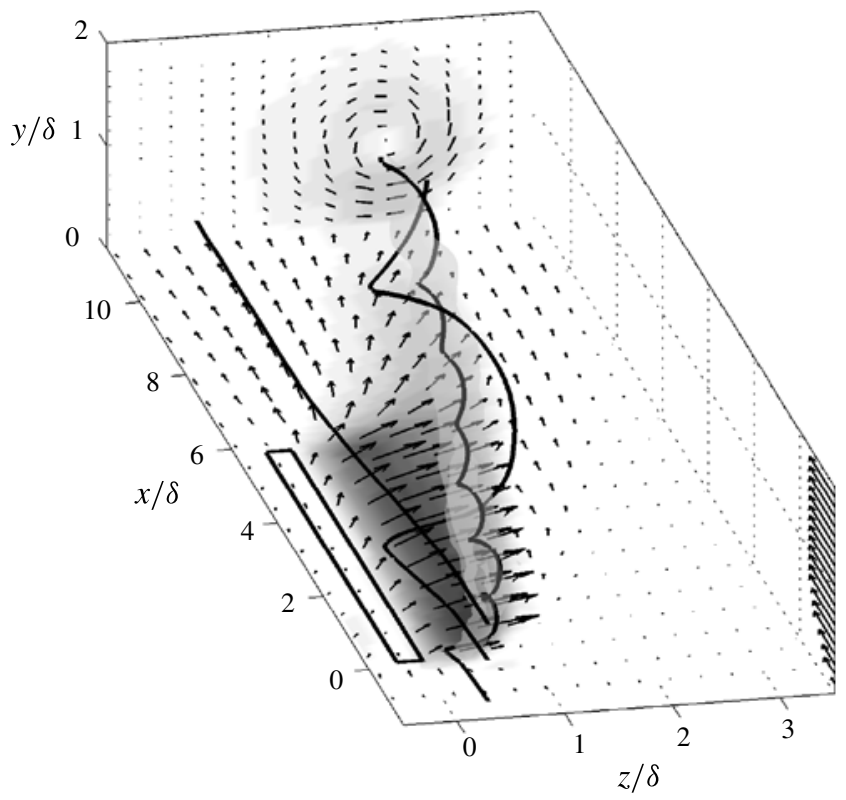

FIGURE 8 . DBD-VG1 in a laminar boundary layer: $U-W$ velocity vectors at $y / \delta=0.05$ and $V-W$ velocity vectors at $x / \delta=11.4$. Coloured by $\sqrt{ }\left(V^{2}+W^{2}\right) / U_{\infty}$. Streamline issued from $x / \delta=-1.5, y / \delta=[0.1,0.5,0.9]$ and $z / \delta=0.3$. 


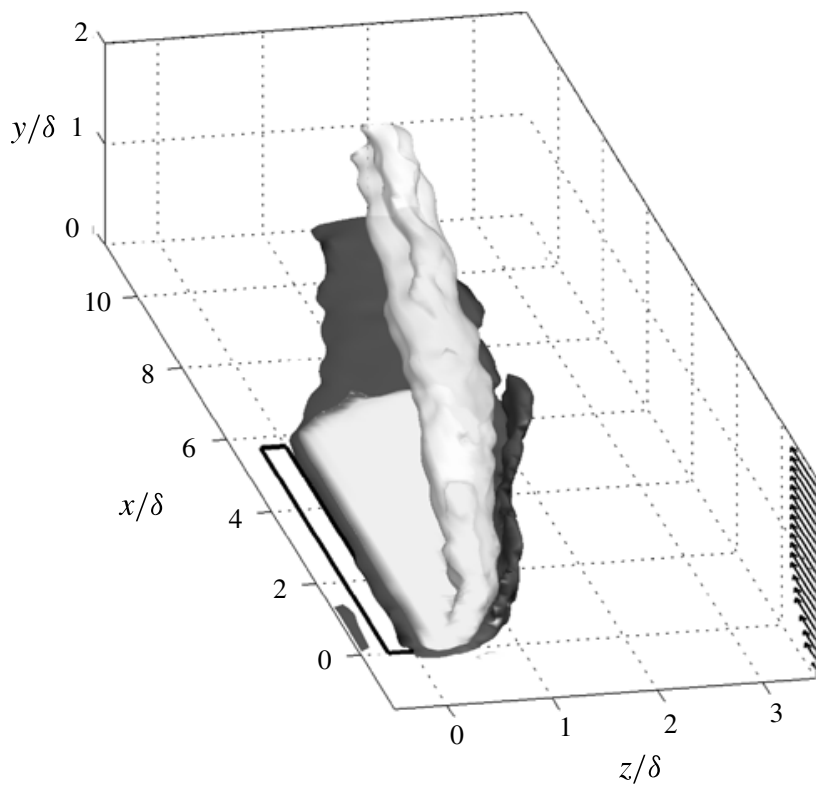

FIGURE 9. Streamwise vorticity isosurfaces around DBD-VG1: $\Omega_{x} \delta / U_{\infty}=1.6$ (dark grey); $\Omega_{x} \delta / U_{\infty}=-1.6$ (white).

The DBD-VG also induces large wall-normal velocity component in addition to the streamwise vortex. This is similar to observed in quiescent air in figure 4(a), which is caused because the plasma is a source of momentum, not mass. This process is demonstrated in figure 8 , where streamlines that initiate near the wall are entrained into the plasma and then undergo rapid lateral acceleration by the EHD body force. They then lift from the wall on the outboard side of the vortex and spiral around the vortex core. Meanwhile streamlines from the outer flow are induced towards the wall above the DBD, so that fluid from the outer boundary layer is brought closer to the wall in the downstream by entrainment into the plasma. The $y-z$ plane velocity field at $x / \delta=11.4(x / l=2)$ clearly depicts a single streamwise vortex with counter-clockwise rotation. No vortex was observed on the $-z$ side of the DBD-VG.

The entrainment into the plasma dramatically reduces the boundary-layer thickness along the length of the DBD-VG and in the downstream. This is particularly apparent in figure 6 , where $\delta$ is reduced by more than $70 \%$ directly downstream of DBD-VG1 $(x / \delta \geqslant 6,0 \leqslant z / \delta \leqslant 1)$. This is also the case for DBD-VG2 in figure 7 , but for reduced spanwise extent. This effect lasts for long streamwise distance and has been demonstrated to be very useful for flow separation control (Jukes \& Choi 2012; Jukes et al. 2013). Thus, the DBD-VG not only utilizes the mixing effect of a streamwise vortex but has an additional wall-ward motion due to entrainment. This phenomenon makes the DBD-VG more adaptable than a DBD actuator oriented across the span because the downwash occurs for prolonged streamwise distance and can be extended and widened simply by increasing $l$.

So how does the negative vorticity in the upper portion of the wall jet roll up to create a concentrated streamwise vortex? The following mechanism is proposed. First, the spanwise wall jet starts to form along the edge of the upper electrode $(x \geqslant 0)$ by fluid entrained from above and to the $-z$ side of the actuator. This fluid 


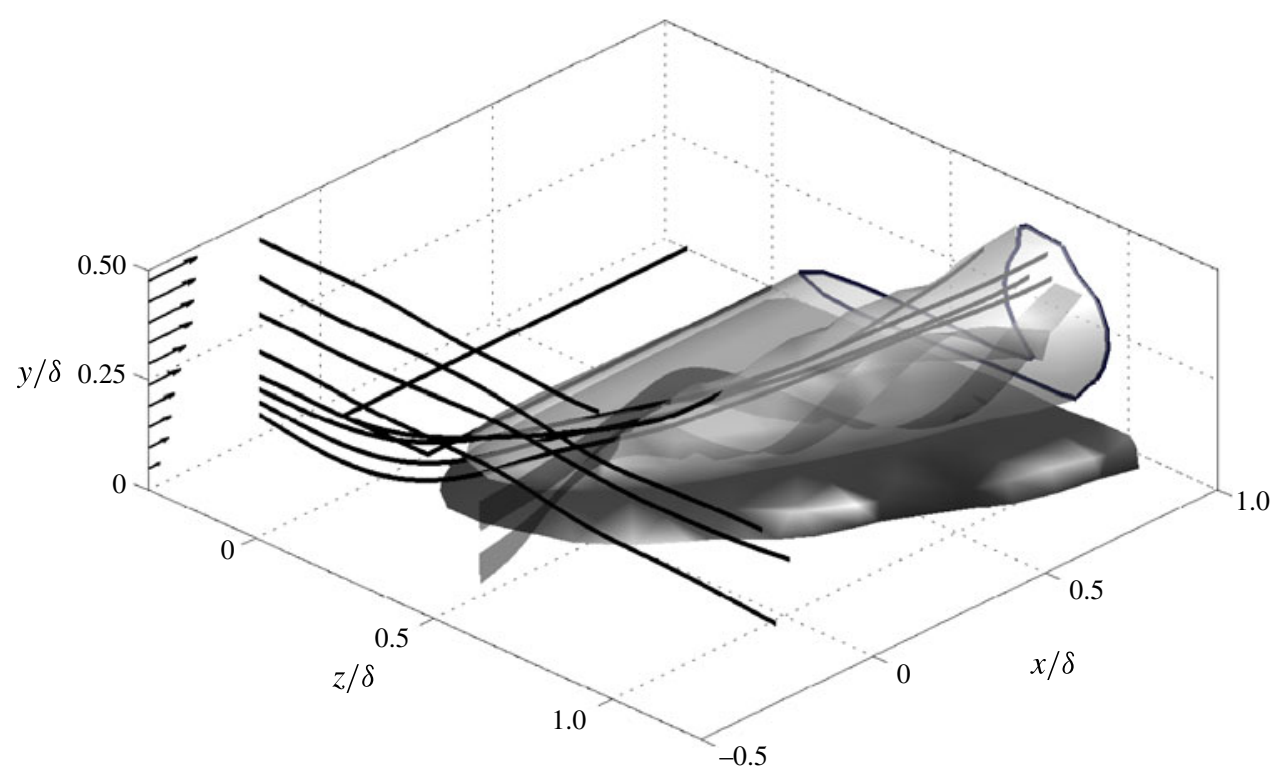

FIGURE 10. Vortex lines with velocity stream-ribbons near the tip of DBD-VG1. Streamwise vorticity isosurfaces: $\Omega_{x} \delta / U_{\infty}=3.5$ (dark grey); $\Omega_{x} \delta / U_{\infty}=-3.5$ (light grey). Vortex lines issued from $x / \delta=-0.2, y / \delta=[0.057,0.086,0.114,0.143,0.200,0.286$, $0.371,0.457]$ and $z / \delta=-0.3$.

is accelerated laterally by the EHD body force to increase $W$ with $z$ within the DBD plasma $(z / \delta \leqslant 0.38$, recall figure $5 a)$. The thickness of the wall jet increases with $z$, although it is much thinner than the oncoming boundary layer and with much higher shear (shown later in figure 12). Consequently the oncoming flow is deflected upwards due to the blockage caused by the jet. This deflection causes spanwise vorticity in the oncoming boundary layer to lift upwards, but this occurs non-uniformly across the span due to the increasing jet thickness. Thus, vortex lines in the boundary layer are initially $z$-directed at the DBD-VG tip (i.e. $\Omega_{z}$ component only), but their $y$ position increases with $z$ due to the thickening of the wall jet. This can be understood more clearly in figure 10, where vortex lines are shown in black originating from $(x / \delta, z / \delta)=(-0.2,-0.3)$. Differential lifting of incoming boundary-layer vorticity over the wall jet causes $+z$-portions of the vortex lines to move into regions of higher $U$, so that they progressively twist into the $x$-direction by the mean flow. Furthermore outboard of the EHD body force region $(z / \delta \geqslant 0.38)$, the jet velocity begins to decay with $z$ so that the flow becomes progressively twisted into the streamwise direction by the boundary layer, like a jet in cross-flow. This lifting and twisting folds the vortex lines in the oncoming boundary layer over and into the upper shear layer of the wall jet and reorients them into the streamwise direction. These two vorticity sources then combine and coalesce into a concentrated streamwise vortex. Vorticity is then added from the upper shear layer of the wall jet along the length of the DBD-VG. Figure 10 shows that by $x / \delta=1$ there is clear distinction between the wall jet, with flat $\pm \Omega_{x}$ vorticity sheets for $y / \delta \leqslant 0.15$ and $z / \delta \leqslant 0.7$, and the streamwise vortex at the jet outer edge $(z / \delta=0.8)$. The vortex formation process is shown schematically in figure 11 .

Figure 12 yields further information regarding the source of streamwise vorticity. As already noted, the spanwise wall jet in figure $12(a)$ is much thinner than the oncoming 


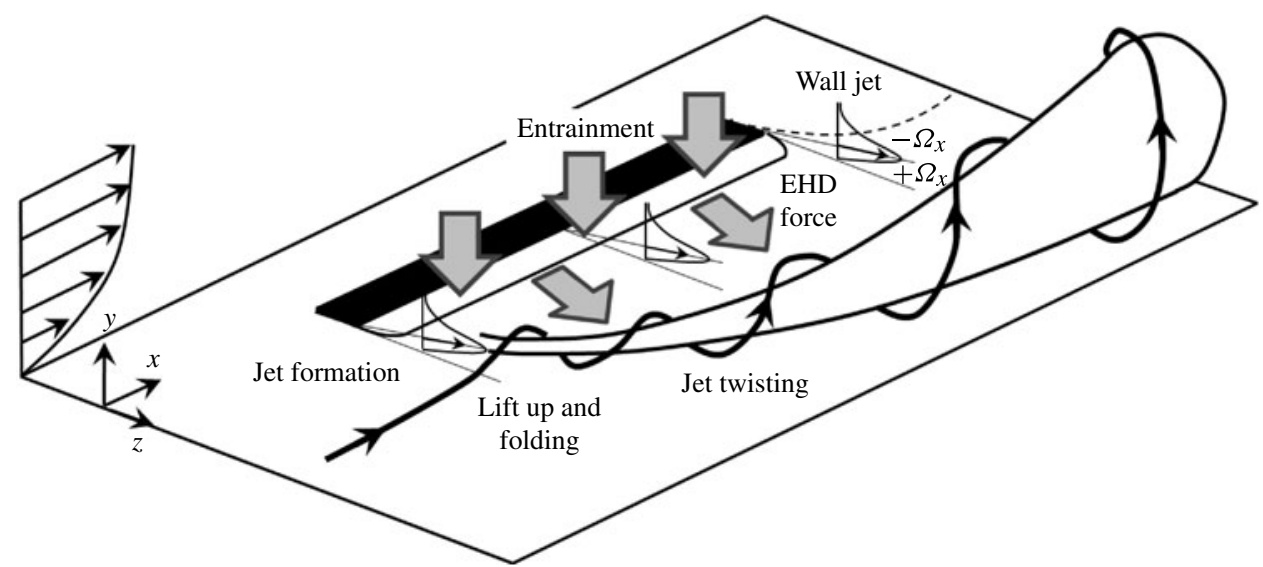

FIGURE 11. Schematic of streamwise vortex creation by DBD-VG.
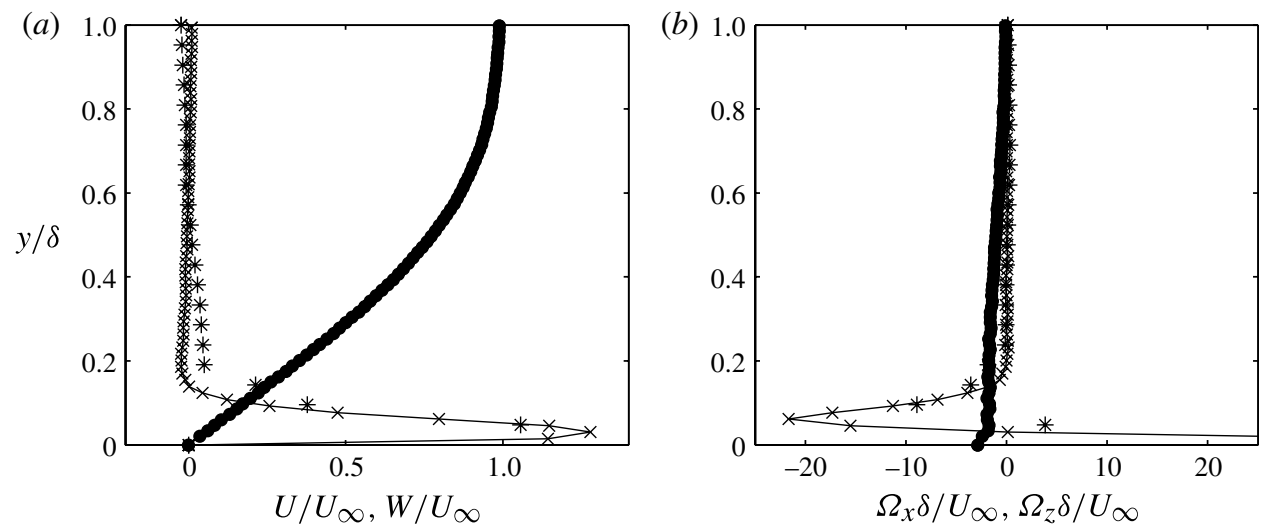

FIGURE 12. Comparison between the boundary layer and wall jet: $(a)$ velocity profile; $(b)$ vorticity profile. - boundary layer; $\times \mathrm{DBD}-\mathrm{VG} 1$ in quiescent air at $z / \delta=0.57(z / l=0.1)$; * DBD-VG1 at DBD-VG trailing edge $x / \delta=5.7$ and $z / \delta=0.57(x / l=1.0$ and $z / l=0.1)$.

boundary layer, but has similar velocity magnitude as $U_{\infty}$. Thus, $-\Omega_{x}$ in the wall jet outer shear layer is nearly one order of magnitude larger than $-\Omega_{z}$ in the oncoming boundary layer (figure $12 \mathrm{~b}$ ). This suggests that skewing of spanwise vorticity into the streamwise direction (i.e. non-zero $\Omega_{z} \partial U / \partial z$ term in the vorticity transport equation, see Bradshaw (1987)), has relatively small contribution to the streamwise vortex in this experiment. Wicks et al. (2012) conjecture that reorientation of mean boundary layer vorticity and direct streamwise vorticity production work in unison in turbulent flow (although only $\partial U / \partial z$ and $\partial V / \partial z$ velocity gradients were measured in their study). Thus, vorticity skewing might be more important for thinner boundary layers or at reduced $W_{p} / U_{\infty}$, but this is not a subject of this study.

\section{Vortex scaling}

Given that the primary source of vorticity is the plasma-induced wall jet, the streamwise vortex formed by the DBD-VG should be analogous to a starting vortex in 

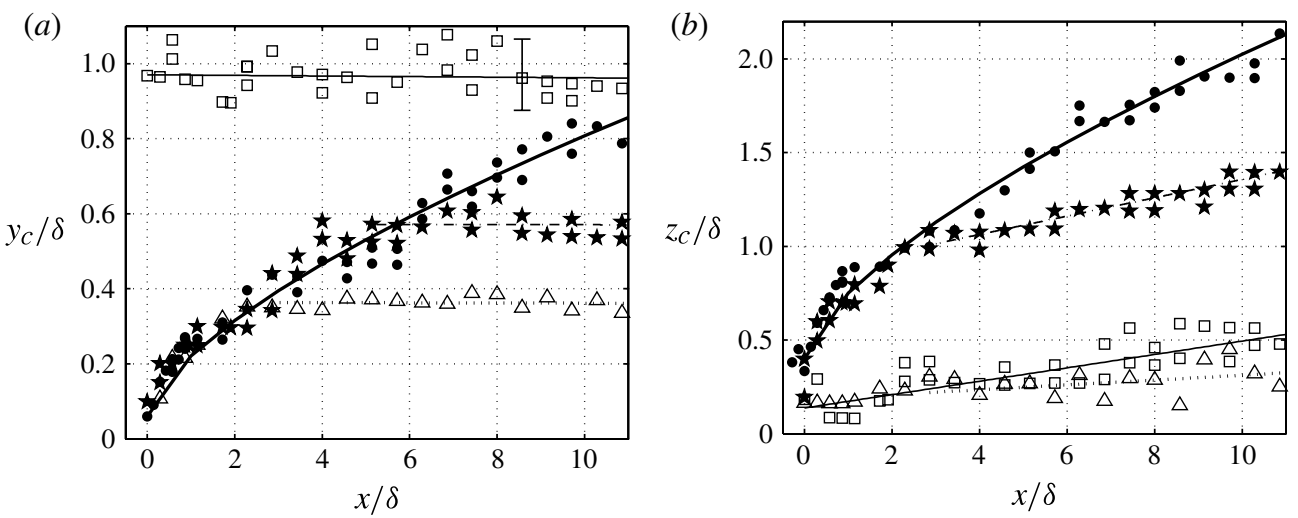

FIGURE 13. Vortex trajectory: DBD-VG1; $\star$ DBD-VG2; $\square$ BL-VG; $\triangle$ LP-VG. $(a)$ Core height, $-y_{c} / \delta=0.16(x / \delta)^{2 / 3}+0.06 ;(b)$ core spanwise location, $-z_{c} / \delta=0.35(x / \delta)^{2 / 3}+$ 0.40 . Scatter indicates PIV data at different $\Delta t$.

quiescent air. The starting vortex from the plasma actuator has already been studied by numerous authors (Jukes et al. 2006a; Corke, Post \& Orlov 2007; Balcon, Benard \& Moreau 2009; Sattari et al. 2012; Whalley \& Choi 2012). Using similarity groups derived by Cantwell (1986), Whalley \& Choi (2012) deduced the self-similarity variables for the DBD starting vortex in quiescent air. Their results show that the wall-parallel and wall-normal distance of the vortex core scales with $t^{2 / 3}$, whilst the vortex circulation scales with $t^{1 / 3}$ because a constant EHD force is produced by the DBD actuator.

Spatially, the similarity variables for the DBD-VG streamwise vortex core can be expressed as $y_{c} \sim x^{2 / 3}$ and $z_{c} \sim x^{2 / 3}$. Figure 13 plots the vortex trajectory, where the vortex core was identified from the location of $-\Omega_{x, \max }$ directly in the $y-z$ plane data. These scaling parameters show good fit to the DBD-VG data, provided that there is an small offset in the vortex origin, $y_{0}$ and $z_{0}$. This confirms that the vortex originates slightly above and to the side of the DBD-VG due to the mechanism described in $\S 4$. Here $y_{0} / \delta=0.06$ and $z_{0} / \delta=0.40$, which are similar to earlier work (Jukes \& Choi 2012). DBD-VG2 core trajectory is nearly identical to DBD-VG1 in the initial stages, but the core height tends to saturate at $y_{c} / \delta \approx 0.6$ beyond $4 \delta$ downstream of the $\mathrm{VG}(x / \delta \geqslant 6$ and $x / l \geqslant 3)$, with reduced spanwise displacement. It is interesting to note that the trajectory of the DBD-VG streamwise vortex is slightly shallower than a starting vortex. The streamwise vortex travels at angle $\theta=24^{\circ}$ to the wall, whereas Whalley \& Choi (2012) observed $\theta=31^{\circ}$ in quiescent air.

The vortex circulation, $\Gamma$, was estimated by integrating the streamwise vorticity at each $y-z$ plane, $\Gamma=\int \Omega_{x} \mathrm{~d} A$. To avoid integrating noise in quiescent regions the integration area, $A$, was determined by an absolute vorticity threshold $\Omega_{x} \leqslant-100 \mathrm{~s}^{-1}$ $\left(\approx 0.05 \Omega_{x, \max }\right)$. Figure $14(a, b)$ shows the development of $\Gamma$ and $\Omega_{x, \max }$, respectively. Similarly, the circulation along the DBD-VGs in figure 14(a) can be scaled by $\Gamma \sim x^{1 / 3}$, except near the DBD-VG tip where the vortex is forming $(x / \delta \lesssim 1)$. Here $\Gamma$ steadily increases along the actuator length before reaching a peak at the actuator trailing edge. Then $\Gamma$ is reduced downstream due to viscous stresses near the wall. DBD-VG2 has one-third the length of DBD-VG1, so that the wall jet acts over much reduced distance. Thus the vortex development in figure 14(a) shows similar increase in circulation, $\Gamma \sim x^{1 / 3}$, but only until the DBD-VG trailing edge 

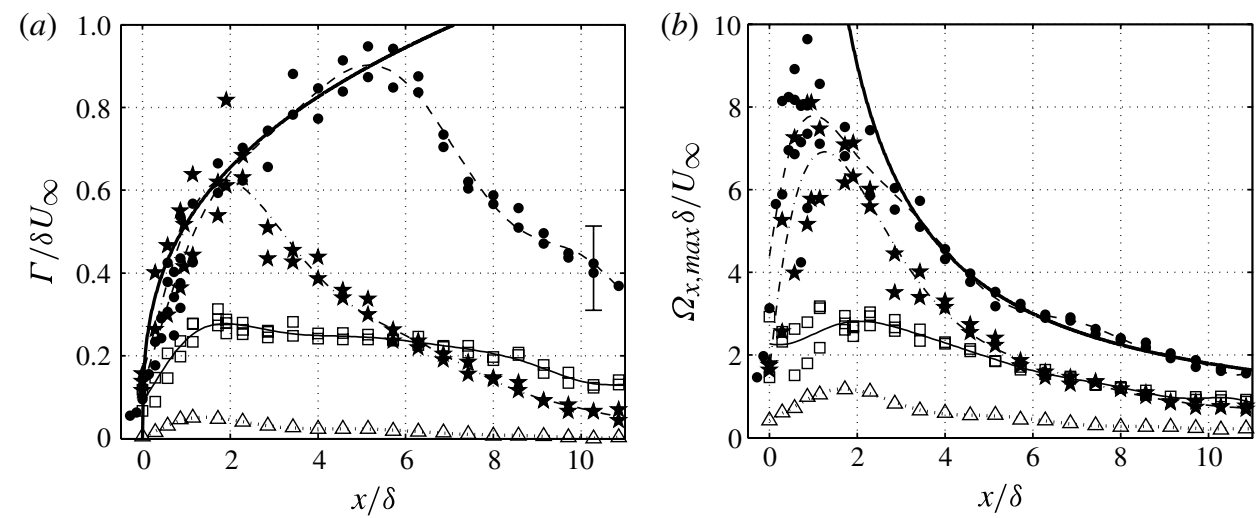

FIgURE 14. Vortex development: DBD-VG1; « DBD-VG2; $\square$ BL-VG; $\triangle$ LP-VG. (a) Vortex circulation, $-\Gamma / \delta U_{\infty}=0.52(x / \delta)^{1 / 3} ;$ (b) peak streamwise vorticity, $-\Omega_{x, \max } \delta / U_{\infty}=18(x / \delta)^{-1}$. Scatter indicates PIV data at different $\Delta t$.

at $x / \delta=1.9(x / \delta=5.7$ for DBD-VG1). The trailing-edge circulation is consequently reduced to $(1 / 3)^{1 / 3}=69 \%$ that of DBD-VG1. Peak vorticity in figure $14(b)$ increases to a maximum at around $x / \delta \approx 1$ whilst the vortex forms, then decays with scaling $\Omega_{x} \sim \Gamma / A \sim x^{1 / 3} / x^{4 / 3} \sim x^{-1}$.

This vortex scaling shown in figure 14 implies that it is the plasma jet that contributes to the circulation of the streamwise vortex, not the oncoming boundary layer. It also implies that the streamwise vortex growth depends upon the wall jet length and velocity scales, not those of the external flow. These were demonstrated by Jukes \& Choi (2012), who studied the vorticity with free-stream speed and the length of the exposed electrode, where the vortex circulation at a range of flow conditions collapsed when scaled with the spanwise wall jet thickness and the wall jet velocity, $\Gamma / W_{p} \delta_{p}$. This idea can now been expanded to conclude that the DBD-VG streamwise vortex location scales with $x^{2 / 3}$, the circulation scales with $x^{1 / 3}$ and the peak vorticity scales with $x^{-1}$. These exponents are in agreement with the similarity law of the starting vortex obtained by Whalley \& Choi (2012) which therefore implies that the plasma produces a constant force along the actuator length.

\section{DBD-VG and vane-type VG comparison}

Now that the plasma VG is understood in low-Reynolds-number flows, we turn our attention to comparing the device to a conventional VG. Figure 15(a) shows the vortex created by DBD-VG2, while figures $15(b)$ and $15(c)$ show the vortices from BL-VG and LP-VG, respectively. Recall that DBD-VG2 has identical length to BL-VG and the maximum plasma-jet velocity is a reasonable match to the velocity at the vane tip $\left(l / \delta=1.9, W_{p} / U_{\infty}=1.25, U_{h} / U_{\infty}=1.0\right)$. Note that the $\lambda_{2}$ vortex indicator is plotted at the same isocontour value for DBD-VG2 and BL-VG, but a factor of 10 lower for LP-VG.

In terms of the vortex-formation mechanism, BL-VG can be thought of as thin, low-aspect-ratio aerofoil that protrudes normal to the surface with $\beta$ equivalent to the aerofoil angle of attack. The streamwise vortex can therefore be considered as a wingtip vortex (Bushnell 1992), created due to a pressure difference between the upstream and downstream vane surfaces. The uppermost streamlines in figure $15(b)$ show the 

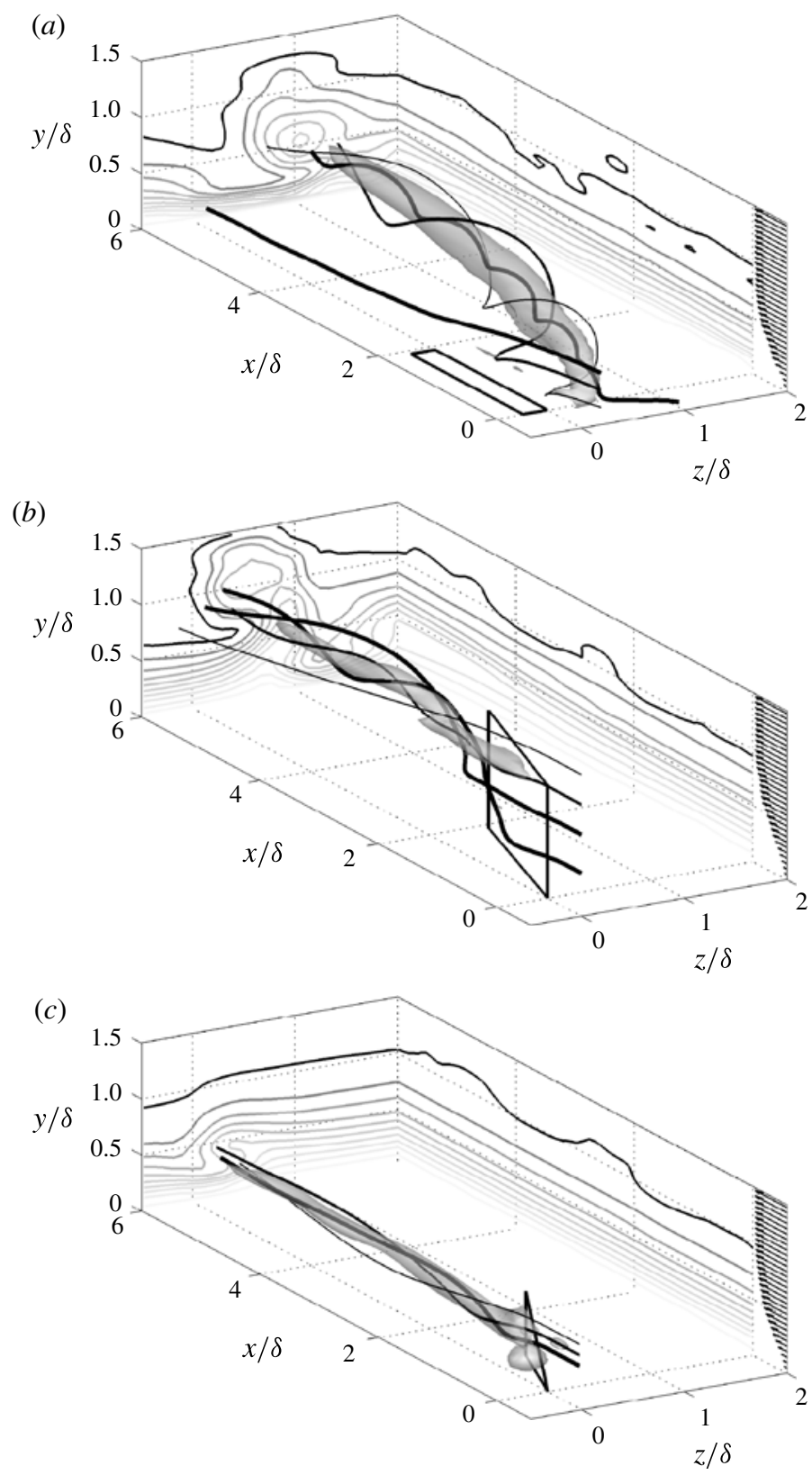

FIGURE 15. Streamwise vortex visualization: (a) DBD-VG2, $\lambda_{2}=-6.5 \times 10^{4} ;(b) \mathrm{BL}-\mathrm{VG}$, $\lambda_{2}=-6.5 \times 10^{4} ;(c)$ LP-VG, $\lambda_{2}=-0.65 \times 10^{4}$. Velocity isocontours: $0 \leqslant U / U_{\infty} \leqslant 1$ in 0.1 increments (light to dark). Streamline issued from $x / \delta=-0.6$. VGs marked by black boxes.

flow is swept upwards on the upstream side (pressure surface) and downwards on the downstream side of the VGs (suction surface). This initiates the vortex-formation process due to the transverse pressure gradient. Unlike a typical wing-tip vortex, the vortex is not shed from the trailing edge but originates from the VG mid-chord. Nearly identical flow fields were observed by Yao et al. (2002) for the same BL-VG 
geometry at much higher Reynolds number $\left(R e_{x}=5200000\right.$ and $\left.U_{\infty}=34 \mathrm{~m} \mathrm{~s}^{-1}\right)$. They hypothesized that the flow around this BL-VG might be slightly stalled due to large $\beta$, so that the vortex only covers a small portion of the vane height. The lower streamline in figure $15(b)$ supports this conclusion, where flow separation appears to be occurring over the suction surface near the wall.

$\mathrm{BL}-\mathrm{VG}$ in figure $15(b)$ creates a single counter-rotating streamwise vortex with similar structure to DBD-VG2. Comparing the velocity contours at $x / \delta=6$ suggests that both streamwise vortices are of similar size, but the BL-VG vortex is weaker (indicated by less helical streamline trajectories in figure $15 b$ and reduced $\Gamma$ and $\Omega_{x, \max }$ in figure 14). As expected, the boundary layer becomes thinner on the downwash side of the vortex and thicker on the upwash side. However, BL-VG lacks the strong wall-ward motion behind the actuator due to the entrainment into the DBD-VG wall jet. Also the BL-VG vortex originates near the vane tip so is located further from the wall. Indeed the trajectory in figure 13 shows that unlike DBD-VG2, this streamwise vortex travels at relatively fixed height, $y_{c} / \delta \approx 1$, with only small lateral translation with $x$. However, the slope $\mathrm{d} z_{c} / \mathrm{d} x$ of $\mathrm{BL}-\mathrm{VG}$ is similar to that of DBD-VG2 in the far field, suggesting that the rate of vortex development in the spanwise direction is identical. The vortex development in figure 14 shows that BL-VG produces less than half the circulation and vorticity of DBD-VG2, despite similar velocity and length scales. The $\Omega_{x, \max }$ decay rate is quite similar and consistent with Yao et al. (2002) for an identical BL-VG. However, the decay of $\Gamma$ is much slower than DBD-VG2, which is expected to be because the vortex is located further from the wall.

The LP-VG vortex is much smaller in diameter (figure 15c), although it is located at similar wall-normal position to DBD-VG2. The boundary layer is again thickened/thinned on the upwash/downwash sides of the vortex, respectively, but the effect is much less dramatic than either DBD-VG2 or BL-VG. This vortex also originates near the vane tip and has relatively fixed core location along the streamwise direction (figure 13). However, there is some short development length similar to DBD-VG2, whereby the vortex core height increases due to the triangular vane profile. If figure 13(a) were replotted in terms of $y_{c} / l$ versus $x / l$, the measured data would collapse on to each other. This suggests that there is a strong similarity in the vortexformation mechanism between the DBD-VG and the triangular BL-VG. Figure 13(b) indicates that the vortex does not make much spanwise translation, but the slope $\mathrm{d} z_{c} / \mathrm{d} x$ is similar to that of DBD-VG2. Naturally the LP-VG vortex is closer to the wall due to the reduced vane height, which increases dissipation to cause a faster $\Gamma$ decay. Even so, figure 14 shows that LP-VG produces an order of magnitude less $\Gamma$ and $\Omega_{x, \max }$ compared with the other VGs. Despite this reduction in vortex strength, this is an optimal VG for flow separation control (according to Godard \& Stanislas (2006)).

The DBD-VG vortex is produced through twisting of a spanwise wall jet, whilst the vane-type VG vortex is produced through the sweeping of fluid over the vane tip. Thus, the vortex-formation mechanisms are quite different, although there is some similarity between the DBD-VG and the triangular LP-VG. DBD-VGs can create streamwise vortices to aid cross-stream momentum transfer like vane-type VGs, whilst also inducing a wall-ward flow above and in the downstream of the actuator. This extra wall-ward flow should be an additional advantage for flow separation control. It should also be noted that the vortex strength and trajectory can be easily adjusted for DBD-VGs simply by changing the plasma excitation parameters (Jukes \& Choi 2012), whilst being rapidly deployed as demanded without device drag. 


\section{Conclusions}

The streamwise vortex produced by a DBD-VG has been studied to identify the vortex-formation mechanisms with a comparison with vane-type VGs. A single, asymmetric plasma actuator was aligned along the streamwise direction to produce an EHD body force into the spanwise direction only. This produced a spanwise-directed wall jet that emanates from the edge of the actuator and becomes twisted into the streamwise direction by the oncoming boundary layer. It is the negative vorticity at the outer edge of the upper shear layer that rolls up to form the streamwise vortex. The vortex formation is initiated by lifting and folding of spanwise vorticity in the oncoming boundary layer over the spanwise wall jet near the DBD-VG tip. This twists the boundary layer spanwise vorticity into the streamwise direction where it rolls up and combines with the streamwise vorticity in the upper shear layer of the wall jet to produce a concentrated streamwise vortex. Once created, the vortex is supplied with streamwise vorticity from the outer layer of a spanwise wall jet to increase the circulation until the trailing edge of the DBD-VG. Thereafter, the vortex decays due to viscous dissipation at the wall. The vortex exhibits self-similar scaling akin to a spatially developing starting vortex, where the wall-parallel and normal distances of the vortex core scale with $x^{2 / 3}$, the circulation scales with $x^{1 / 3}$, and the peak vorticity scales with $x^{-1}$.

In contrast, the streamwise vortex from vane-type VGs are created due to pressure difference across the windward and leeward faces, similar to the wing-tip vortex from low-aspect-ratio aerofoils. Thus, the vortex strength is governed by the oncoming flow velocity at the vane tip, whereas the DBD-VG vortex strength is governed by the velocity in the spanwise wall jet. In these experiments, the DBD-VG was able to produce a streamwise vortex that was much closer to the wall and more than a factor of two stronger than a $\delta$-scale vane-type VG of similar length and velocity scales. Furthermore the DBD-VG vortex was an order of magnitude stronger than an optimal low-profile VG.

In addition to the streamwise vortex, the DBD-VG induces a strong downwash motion directly above the plasma because the DBD is a source of momentum, not mass. Therefore, fluid must be entrained into the plasma to replace that accelerated laterally into the wall jet due to mass continuity. This wall-ward entrainment leads to a significant thinning of the boundary layer in the downstream of the DBD-VG. This phenomenon is supplementary to the creation of a streamwise vortex. Thus, the DBD-VG not only utilizes the mixing effect of streamwise vorticity, but also induces wall-ward velocity component which may offer extra advantages for flow separation control.

In terms of practical application of plasma VGs on aircraft, there are several factors that must be considered. First, the effectiveness of plasma actuators depends on atmospheric pressure, where plasma-induced velocity (Benard, Balcon \& Moreau 2008a) and thrust (Abe et al. 2007) are maximized in air of around 0.7 atmospheres. This is conjectured to be due to a compromise between higher ionization at lower pressure and greater collisional momentum transfer at higher pressure (Benard et al. 2008a). Thus, plasma VGs would be most effective during landing and take-off, where they are most likely to be required, but would probably perform poorly at cruise altitude. Humidity, however, has a detrimental effect whereby performance rapidly deteriorates when the relative humidity increases beyond $85 \%$ (Benard, Moreau \& Balcon 2009), although plasma formation is still possible under these conditions. Surface water, in contrast, can be simply evapourated off after a few seconds (Patel et al. 2008), after which plasma formation resumes as normal. DBD plasma can also 
be created at elevated temperatures (Segawa et al. 2007), although the effect of low temperatures and icing is as yet undocumented to the best of the authors' knowledge. Probably the greatest challenge is to increase the actuator authority sufficiently to create strong streamwise vortices in high-speed flow. For example, Jukes \& Choi (2012) demonstrated flow separation control at $W_{p} / U_{\infty}<0.1$, but the plasma velocity has so far remained limited to $W_{p}<10 \mathrm{~m} \mathrm{~s}^{-1}$ (Forte et al. 2007). Further study at higher Reynolds number is required to see whether these VGs can perform under flight conditions.

\section{Acknowledgements}

The work has been carried out as a part of the European Community's Seventh Framework Programme PlasmAero under grant agreement no. 234201. An overview of PlasmAero can be found in Caruana (2010). Funding from the University of Nottingham Advance Research Fellowship (NARF) is gratefully acknowledged. We would also like to acknowledge EPSRC Research Grant EP/G025150/1, under which the PIV system that was used in this study was purchased.

\section{REFERENCES}

Abe, T., Takizawa, Y., Sato, S. \& Kimura, N. 2007 A parametric experimental study for momentum transfer by plasma actuator. In 45th AIAA Aerospace Sciences Meeting, AIAA Paper 2007-187. American Institute of Aeronautics and Astronautics.

Angele, K. \& GREwe, F. 2007 Instantaneous behaviour of streamwise vortices for turbulent boundary layer separation control. Trans. ASME: J. Fluids Engng 129 (2), 226-235.

Balcon, N., Benard, N. \& Moreau, E. 2009 Formation process of the electric wind produced by a plasma actuator. IEEE Trans. Dielec. Elec. Insul. 16 (2), 463-469.

Benard, N., BALCON, N. \& Moreau, E. $2008 a$ Electric wind produced by a surface dielectric barrier discharge operating in air at different pressure: aeronautical control insights. J. Phys. D: Appl. Phys. 41, 042002.

Benard, N., Jolibois, J., Touchard, G. \& Moreau, E. $2008 b$ A directional plasma-jet device generated by double DBD actuators: an active vortex generator for aerodynamic flow control. In 4th AIAA Flow Control Conference, AIAA Paper 2008-3763. American Institute of Aeronautics and Astronautics.

Benard, N. \& Moreau, E. 2012 Role of the electric waveform supplying a dielectric barrier discharge plasma actuator. Appl. Phys. Lett. 100, 193503.

Benard, N., Moreau, E. \& Balcon, N. 2009 Electric wind produced by a surface dielectric barrier discharge operating over a wide range of relative humidity. In 47th AIAA Aerospace Sciences Meeting, AIAA Paper 2009-488. American Institute of Aeronautics and Astronautics.

Boeuf, J. P., Lagmich, Y., Unfer, Th., Callegari, Th. \& Pitchford, L. C. 2007 Electrohydrodynamic force in dielectric barrier discharge plasma actuators. J. Appl. Phys. D: Appl. Phys. 40, 652-662.

Bradshaw, P. 1987 Turbulent secondary flows. Annu. Rev. Fluid Mech. 19, 53-74.

Bushnell, D. 1992 Longitudinal vortex control - techniques and applications (the 32nd Lanchester lecture). Aeronaut. J. 96, 293-312.

Cantwell, B. J. 1986 Viscous starting jets. J. Fluid Mech. 173, 159-189.

Caruana, D. 2010 Plasmas for aerodynamic control. Plasma Phys. Control. Fusion 52, 124045.

Chan, S., Zhang, X. \& GABRiel, S. 2007 Attenuation of low-speed flow-induced cavity tones using plasma actuators. AIAA J. 45 (7), 1525-1538.

Choi, K.-S., Jukes, T. N. \& Whalley, R. D. 2011 Turbulent boundary-layer control with plasma actuators. Phil. Trans. R. Soc. A 369, 1443-1458.

Corke, T., Bowles, P., He, C. \& Matlis, E. 2011 Sensing and control of flow separation using plasma actuators. Phil. Trans. R. Soc. A 369, 1459-1475. 
Corke, T., He, C. \& PAtel, M. 2004 Plasma flaps and plasma slats: an application of weakly-ionized plasma actuators. In 2nd AIAA Flow Control Conference, AIAA Paper 2004-2127. American Institute of Aeronautics and Astronautics.

Corke, T., Post, M. \& Orlov, D. 2007 SDBD plasma enhanced aerodynamics: concepts, optimization and applications. Prog. Aerospace Sci. 43, 193-217.

Corke, T., Post, M. \& Orlov, D. 2009 Single dielectric barrier discharge plasma enhanced aerodynamics: physics, modelling and applications. Exp. Fluids 46, 1-26.

Cortelezzi, L. \& Karagozian, A. 2001 On the formation of the counter-rotating vortex pair in transverse jets. J. Fluid Mech. 446, 347-373.

Enloe, C., Mcharg, M., Font, G. \& Mclaughlin, T. 2009 Plasma-induced force and self-induced drag in the dielectric barrier discharge aerodynamic plasma actuator. In 47th AIAA Aerospace Sciences Meeting, AIAA Paper 2009-1622. American Institute of Aeronautics and Astronautics.

Enloe, C. L., Mclaughlin, T. E., Vandyken, R. D., Kachner, K. D., Jumper, E. J. \& CORKE, T. C. 2004a Mechanisms and responses of a single dielectric barrier plasma actuator: plasma morphology. AIAA J. 42 (3), 589-594.

Enloe, C. L., Mclaughlin, T. E., Vandyken, R. D., Kachner, K. D., Jumper, E. J., Corke, T. C., Post, M. \& Hadded, O. 2004b Mechanisms and responses of a single dielectric barrier plasma actuator: geometrics effects. AIAA J. 42 (3), 595-604.

Feng, L., Jukes, T., ChOI, K.-S. \& WANG, J. J. 2012 Flow control over a NACA 0012 airfoil using dielectric-barrier-discharge plasma actuator with a gurney flap. Exp. Fluids 52, $1533-1546$.

Forte, M., Jolibois, J., Pons, J., Moreau, E., Touchard, G. \& Cazalens, M. 2007 Optimization of a dielectric barrier discharge actuator by stationary and non-stationary measurements of the induced flow velocity: application to airflow control. Exp. Fluids 43, 917-928.

Gibalov, V. \& Pietsch, G. 2000 The development of dielectric barrier discharges in gas gaps and on surfaces. J. Phys. D: Appl. Phys. 33, 2618-2636.

Glauert, M. B. 1956 The wall jet. J. Fluid Mech. 1, 625-643.

GodARD, G. \& STANislas, M. 2006 Control of a decelerating boundary layer. Part 1: optimization of passive vortex generators. Aerosp. Sci. Technol. 10, 181-191.

Greenblatt, D., Goksel, B., Rechenberg, I., Schule, C. Y., Romann, D. \& Paschereit, C. O. 2008 Dielectric barrier discharge flow control at very low flight reynolds numbers. AIAA J. 46 (6), 1528-1541.

Greenblatt, D., Schneider, T. \& Schule, C. Y. 2012 Mechanism of flow separation control using plasma actuation. Phys. Fluids 24, 077102.

Grundmann, S., SaYles, E. \& EATON, J. 2011 Sensitivity of an asymmetric 3D diffuser to plasma-actuator induced inlet condition perturbations. Exp. Fluids 50, 217-231.

Grundmann, S., Sayles, E., Elkins, C. \& Eaton, J. 2012 Sensitivity of an asymmetric 3D diffuser to vortex-generator induced inlet condition perturbations. Exp. Fluids 52, 11-21.

Grundmann, S. \& TropeA, C. 2008 Active cancellation of artificially introduced tollmienschlichting waves using plasma actuators. Exp. Fluids 44, 795-806.

Hanson, R., Lavoie, P., Nagiub, A. \& Morrison, J. 2010 Transient growth instability cancelation by a plasma actuator array. Exp. Fluids 49, 1339-1348.

He, C., Corke, T. \& PAtel, M. 2007 Numerical and experimental analysis of plasma flow control over a hump model. In 45th AIAA Aerospace Sciences Meeting, AIAA Paper 2007-935. American Institute of Aeronautics and Astronautics.

He, C., Corke, T. C. \& PATEl, M. P. 2009 Plasma flaps and slats: an application of weakly ionized plasma actuators. J. Aircraft 46 (3), 864-873.

Huang, J., Corke, T. C. \& Thomas, F. O. $2006 a$ Plasma actuators for separation control of low-pressure turbine blades. AIAA J. 44 (1), 51-57.

Huang, J., Corke, T. C. \& Thomas, F. O. $2006 b$ Unsteady plasma actuators for separation control of low-pressure turbine blades. AIAA J. 44 (7), 1477-1487.

HuAng, X. \& ZhAng, X. 2008 Streamwise and spanwise plasma actuators for flow-induced cavity noise control. Phys. Fluids 20, 037101. 
IM, S., Do, H. \& CAPPElli, M. 2010 Dielectric barrier discharge control of a turbulent boundary layer in a supersonic flow. Appl. Phys. Lett. 97, 041503.

JeOng, J. \& Hussain, F. 1995 On the indentification of a vortex. J. Fluid Mech. 285, 69-94.

Johnston, J. P. 1999 Pitched and skewed vortex generator jets for control of turbulent boundary layer separation: a review. In 3rd ASME/JSME Joint Fluids Engineering Conference, FEDSM99-6917.

Johnston, J. P. \& Nishi, M. 1990 Vortex generator jets - means for flow separation control. AIAA J. 28 (6), 989-994.

JUKES, T. \& CHOI, K.-S. $2009 a$ Control of unsteady flow separation over a circular cylinder using dielectric-barrier-discharge surface plasma. Phys. Fluids 21, 094106.

JUKes, T. \& CHOI, K.-S. 2009b Flow control around a circular cylinder using pulsed dielectric barrier discharge surface plasma. Phys. Fluids 21, 084103.

JUKES, T. \& CHOI, K.-S. 2009c Long lasting modifications to vortex shedding using a short plasma excitation. Phys. Rev. Lett. 102, 254501.

JuKes, T. \& CHOI, K.-S. 2012 Dielectric-barrier-discharge vortex generators: characterisation and optimisation for flow separation control. Exp. Fluids 52, 329-345.

Jukes, T., Choi, K.-S., Johnson, G. \& ScotT, S $2006 a$ Characterisation of surface plasma-induced wall flows through velocity and temperature measurement. AIAA J. 44 (4), 764-771.

Jukes, T., Choi, K.-S., ScotT, S. \& Johnson, G. $2006 b$ Turbulent drag reduction by surface plasma through spanwise flow oscillation. In 3rd AIAA Flow Control Conference, AIAA Paper 2006-3693. American Institute of Aeronautics and Astronautics.

Jukes, T., Segawa, T. \& Furutani, H. 2013 Flow control on a NACA 4418 using dielectric-barrier-discharge vortex generators. AIAA J. 51 (2), 452-464.

Kelso, R., Lim, T. \& Perry, A. 1996 An experimental study of round jets in cross-flow. J. Fluid Mech. 306, 111-144.

Khan, Z. \& Johnston, J. 2000 On vortex generator jets. Intl J. Heat Fluid Flows 21, 506-511.

Kogelschatz, U., Eliasson, B. \& Egli, W. 1997 Dielectric-barrier discharges. Principle and applications. J. Physique IV 7 (C4), 47-66.

Kozlov, A. \& Thomas, F. 2011 Bluff-body flow control via two types of dielectric barrier discharge plasma actuation. AIAA J. 49 (9), 1919-1931.

Kriegseis, J., Schwarz, C., Duchmann, A., Grundmann, S. \& Tropea, C. 2012 PIV-based estimation of DBD plasma-actuator force terms. In 50th AIAA Aerospace Sciences Meeting, AIAA Paper 2012-0411. American Institute of Aeronautics and Astronautics.

LIN, J. 2002 Review of research on low-profile vortex generators to control boundary-layer separation. Prog. Aerospace Sci. 38, 389-420.

Little, J., Nishinara, M., Adamovich, I. \& Samimy, M. 2010 High-lift airfoil trailing edge separation control using a single dielectric barrier discharge plasma actuator. Exp. Fluids 48, 521-537.

LögdberG, O., Angele, K. \& Alfredsson, H. 2010 On the robustness of separation control by streamwise vortices. Eur. J. Mech. (B/Fluids) 29, 9-17.

Mehta, R. \& BRadshaw, P. 1988 Longitudinal vortices imbedded in turbulent boundary layers. Part 2. Vortex pair with 'common flow' upwards. J. Fluid Mech. 188, 529-546.

Moreau, E. 2007 Airflow control by non-thermal plasma actuators. J. Phys. D: Appl. Phys. 40 (3), 605-636.

OKitA, Y., Jukes, T., ChOI, K.-S. \& NAKAMURA, K. 2008 Flow reattachment over an airfoil using surface plasma actuator. In 4th AIAA Flow Control Conference, AIAA Paper 2008-4203. American Institute of Aeronautics and Astronautics.

Patel, M., Vasudevan, S., Nelson, R. \& Corke, T. 2008 Plasma aerodynamic control effectors for improved wind turbine performance. Tech. Rep. Phase I SBIR Final Report.

Pauley, W. \& EAton, J. 1988 Experiment study of the development of longitudinal vortex pairs embedded in a turbulent boundary layer. AIAA J. 26 (7), 816-823.

Post, M. L. \& CoRKe, T. C. 2006 Separation control using plasma actuators: dynamic stall vortex control on oscillating airfoil. AIAA J. 44 (12), 3125-3135. 
Roth, J., Sherman, D. \& Wilkinson, S. 1998 Boundary layer flow control with a one atmosphere uniform glow discharge surface plasma. In 36th AIAA Aerospace Sciences Meeting, AIAA Paper 98-0328. American Institute of Aeronautics and Astronautics.

Roth, J., Sherman, D. \& Wilkinson, S. 2000 Electrohydrodynamic flow control with a glow-discharge surface plasma. AIAA J. 38 (7), 1166-1172.

Sattari, P, Rival, D., Martinuzzi, R. \& Tropea, C. 2012 Growth and separation of a start-up vortex from a two-dimensional shear layer. Phys. Fluids 24, 107102.

Schatzman, D. \& Thomas, F. 2010 Turbulent boundary-layer separation control with single dielectric barrier discharge plasma actuators. AIAA J. 48 (8), 1620-1634.

Schlichting, H. 1979 Boundary Layer Theory. McGraw-Hill.

Schubauer, G. \& Spangenberg, W. 1960 Forced mixing in boundary layers. J. Fluid Mech. 8, 10-32.

Segawa, T., Furutani, H., Yoshida, H., Jukes, T. \& Choi, K.-S. 2007 Wall normal jet under elevated temperatures produced by surface plasma actuator. In 45th AIAA Aerospace Sciences Meeting, AIAA Paper 2007-784. American Institute of Aeronautics and Astronautics.

Shebaka, I., Mehta, R. \& Bradshaw, P. 1985 Longitudinal vortices imbedded in turbulent boundary layers. Part 1. Single vortex. J. Fluid Mech. 155, 37-57.

Stephen, E., Campbell, A., Nygaard, J., Selby, M., Hennig, C. \& Mclaughlin, T. 2011 Assessment of a corner plasma actuator for flow control using periodic jets. In 29th AIAA Applied Aerodynamics Conference, AIAA Paper 2011-3513. American Institute of Aeronautics and Astronautics.

TAYLOR, H. 1947 The elimination of diffuser separation by vortex generators. Report no. r-4012-3. United Aircraft Corporation.

Tetervin, N. 1948 Laminar flow of a slightly viscous incompressible fluid that issues from a slit and passes over a flat plate. TN 1644. NACA.

Thomas, F., Kozlov, A. \& Corke, T. 2008 Plasma actuators for cylinder flow control and noise reduction. AIAA J. 46 (8), 1921-1931.

Versailles, P., Gingras-Gosselin, V. \& Vo, H. D. 2010 Impact of pressure and temperature on the performance of plasma actuators. AIAA J. 48 (4), 859-863.

Wang, J. J., Choi, K.-S., Feng, L., Jukes, T. \& Whalley, R. 2013 Recent developments in DBD plasma flow control. Prog. Aerospace Sci. 62, 52-78.

Westerweel, J. 1997 Fundamentals of digital particle image velocimetry. Meas. Sci. Technol. 8, 1379-1392.

Whalley, R. \& CHOI, K.-S. 2012 The starting vortex in quiescent air induced by dielectric-barrierdischarge plasma. J. Fluid Mech. 703, 192-203.

Wicks, M., Thomas, F., Schatzman, D., Bowles, P., Corke, T., Patel, M. \& A, Cain 2012 A parametric investigation of plasma streamwise vortex generator performance. In 50th AIAA Aerospace Sciences Meeting, AIAA Paper 2012-0824. American Institute of Aeronautics and Astronautics.

WILKINSON, S. 2003 Oscillating plasma for turbulent boundary layer drag reduction. In 41st AIAA Aerospace Sciences Meeting, AIAA Paper 2003-1023. American Institute of Aeronautics and Astronautics.

YAo, C., Lin, J. \& Allen, B. 2002 Flowfield measurement of device-induced embedded streamwise vortex on a flat plate. In 1st AIAA Flow Control Conference, AIAA Paper 2002-3162. American Institute of Aeronautics and Astronautics.

ZHANG, X. 2003 The evolution of co-rotating vortices in a canonical boundary layer with inclined jets. Phys. Fluids 15, 3693-3702. 